\title{
Mechanical Behavior and Constitutive Model for Loess Samples under Simulated Acid Rain Conditions
}

xia ye

Sichuan University - Wangjiang Campus: Sichuan University

Enlong Liu ( $\sim$ liuenlong@scu.edu.cn )

Sichuan University - Wangjiang Campus: Sichuan University

Baofeng Di

Sichuan University - Wangjiang Campus: Sichuan University

yayang yu

Sichuan University - Wangjiang Campus: Sichuan University

\section{Research Article}

Keywords: Acid rain, Saturated loess samples, Mechanical properties, Porous medium material, The double hardening model, $\mathrm{pH}$ values

Posted Date: April 16th, 2021

DOI: https://doi.org/10.21203/rs.3.rs-355110/v1

License: (c) (i) This work is licensed under a Creative Commons Attribution 4.0 International License. Read Full License

Version of Record: A version of this preprint was published at Scientific Reports on March 9th, 2022. See the published version at https://doi.org/10.1038/s41598-022-08199-9. 
1

\section{Mechanical Behavior and Constitutive Model for Loess}

\section{Samples under Simulated Acid Rain Conditions}

Xia Ye ${ }^{\text {a }}$, Enlong Liu ${ }^{\mathrm{b}}$, Baofeng Di ${ }^{\mathrm{c}}$, Yanyang Yu ${ }^{\mathrm{d}}$

${ }^{a}$ Ph.D. Student, Institute of Disaster Management and Reconstruction, Sichuan University, Chengdu 610041,

China

and Hydropower, Sichuan University, Chengdu 610065, Sichuan, China

${ }^{\mathrm{b}}$ Professor, State Key Laboratory of Hydraulics and Mountain River Engineering, College of Water Resource

${ }^{\mathrm{c}}$ Professor, Institute of Disaster Management and Reconstruction, Sichuan University, Chengdu 610041, China

${ }^{d}$ Ph.D. Student, State Key Laboratory of Hydraulics and Mountain River Engineering, College of Water

Resource and Hydropower, Sichuan University, Chengdu 610065, Sichuan, China

Corresponding author: Professor Enlong Liu; Email: liuenlong@scu.edu.cn.

ABSTRACT: In this paper, the sulfuric acid solution is diluted to $\mathrm{pH} 5.0,4.0$ and 3.0 to simulate the acid rain condition, and the triaxial compressional tests and scanning electron microscope are carried out to study the mechanical properties and evolution of the microstructure of the saturated loess samples.

The results demonstrate that acid rain increases the porosity of loess samples, and the pore distribution is not uniform, so that the mechanical properties of loess samples change. With the decrease of $\mathrm{pH}$ value, the peak value of the deviatoric stress and the volumetric contraction of loess samples decreases, which causes the strength of soil to decrease. Furthermore, the framework of the chemical-mechanical model for loess under the action of acid rain is established, in which the loess is considered as porous medium material, and the variable of acid rain at different $\mathrm{pH}$ values through the degree of chemical reaction is 
taken into account in the double-hardening model, and the model is also verified by the triaxial test results finally.

KEYWORDS: Acid rain; Saturated loess samples; Mechanical properties; Porous medium material; The double hardening model; $\mathrm{pH}$ values;

\section{Introduction}

In recent years, the problem of acid rain is very common, many scholars have found that acid rain will not only destroy the living environment of biological communities, but also aggravate other soil pollution (Wang et al., 2018; Zhu et al., 2018; Liang et al., 2020). Acid rain can accelerate the loss of mineral composition and change the soil structure. As we know, acid rain can corrode buildings, roadbed and pavement, dissolve soil on the surface of roadbed and pavement, and make cracks appear, resulting in reduced strength, thereby damaging the roadbed and pavement, and causing certain risks. For the loess areas located in western zone in China, acid rain can also change the mechanical features and thus damage the ground there. Therefore, the effect of acid rain on the mechanical properties of loess samples should be studied, which can provide a guidance for protecting the building located in loess areas there.

A large number of experimental studies have found that acid rain has an impact on soil strength and other mechanical indicators. In terms of rocks, the indoor uniaxial, shear and triaxial tests on rocks corroded by different $\mathrm{pH}$ values are carried out, and find that it significantly reduces the strength of rocks and causes damage to the rock structure. The corrosion mechanism of acid rain on rock samples is also preliminarily discussed (Ding and Feng, 2009; Xu et al., 2012; Han et al., 2013). The influence of acid rain on the stability of slope is explored, conducted relevant chemical weathering experiments under the action of acid rain, and analyzed the weakening mechanism of acid rain on slope (Zhao et al., 2009; Zhao 
et al., 2019). The leaching effect of acid rain on calcareous sandy loam is simulated, and different $\mathrm{pH}$ aggravates the loss of phosphorus in the soil (Jalali and Naderi, 2012). Huang et al. (2021) found that high temperature and acid chemical solution could affect the mechanical characteristics of rock mass through the physical thermophysical test and Brazilian splitting test of red sandstone samples. The changes of the mechanical properties of composite fine grained soil under the influence of acids with different $\mathrm{pH}$ values is investigated. Because the internal structure of the soil is changed by acid rain, the compressive strength and shear strength parameters of the soil are reduced (Sarkary et al., 2012). (Gratchev and Towhata, 2011; Gratchev and Towhata, 2016; Bakhshipour et al., 2016a; Bakhshipour et al., 2016b; Bakhshipour et al., 2017)they conducted experiments on the influence of acid rain on soil compression characteristics, which led to significant changes in mineral structure with the decrease of $\mathrm{pH}$ values. The study of acid concentration on the mechanical properties of soil is also carried out. Acid has a great influence on the mechanical properties of soil (Hassanlourad et al., 2017; Chavali and Ponnapureddy, 2018; Koupai et al., 2020). Liu et al. (2020) used the laboratory permeability test of undisturbed loess to study the permeability characteristics under the action of three kinds of acid erosion, found the influence of acid concentration on the permeability coefficient, and analyzes its mechanism from the perspective of microstructure changes. It can be seen that the erosion of acid rain will damage the structure of soil and has a very adverse effect on the mechanical properties of soil. The abovementioned scholars mainly conduct related experiments on rock and soil by acid rain, but did not conduct related research on the constitutive relationship.

In recent years, some scholars have studied the constitutive relations of soils (permafrost, overconsolidated soil, saturated soil and rocks) through porous media theory (Yao et al., 2009; Zhang et al., 2012; Shen and Shao, 2016; Zhang, 2017; Liu et al., 2018; Liu and Lai, 2020). Constitutive models of 
the chemical-mechanical behavior of soil under porous media theory are also proposed. (Gawin et al., 2006; Martinelli et al., 2013) they proposed a thermal fluidization model that takes into account the fine and microscopic scale of concrete hardening. A high-precision hydrothermal chemical model for early self-drying phenomena is proposed (Luzio and Cusatis, 2009; Jendele et al., 2014). These scholars have studied the chemical-mechanical model of concrete materials, but have not applied this method to soil materials. For geotechnical materials, the following scholars have done the related research. Sherwood (1993) modified the basic thermodynamic parameters of Biot and the chemical potential related to the pore fluid. (Hueckel, 1997; Gajo et al., 2002) they considered that clay is contaminated in the stress history and study the electro-chemical-mechanical constitutive equation under the elastoplastic condition from the perspective of mass concentration. Nova et al. (2003) proposed a strain hardening elastoplastic model considering the internal plastic strain, weathering and chemical effects of bonded geomaterials. Boukpeti et al. (2004) proposed a model to consider the chemical plastic behavior of organic polluted liquids on clay under vertical flow. Shale was studied and permeability parameters are determined to solve the chemical pore elasticity of the cylinder (Detournay et al., 2005; Bunger, 2010; Sarout and Detournay, 2011). Guimaraes et al. (2007) proposed a thermo-fluid-mechanical coupling model considering the transport of the reaction from the perspective of the total analytical concentration. Kyokawa et al. (2020) established an electro-chemical-mechanical model by considering the deformation characteristics of the chemical composition changes of pore fluids in expansive soil. Song and Menon (2019) applied the principle of state primitives to unsaturated clays and establishes a non-local chemicalhydrodynamic model at the same chemical loading rate. The microstructure of the soil is studied, and the macroscopic model of saturated soil is derived by extending the pore scale to macroscopic scale through the theory of homogenization (Moyne and Murad, 2002; Buscarnera and Das, 2012). Thomas and Clearl 
(1999) proposed an unsaturation-thermo-mechanical coupling model from the perspective of the osmotic potential and chemical solute concentration of expanded clay. Lei et al. (2016) established a thermodynamic framework for unsaturated expansive clay and took into account the situation of ionic expansive clay. These scholars mainly explore the chemical ion exchange that occurs inside the rock and soil, and the chemical concentration changes caused by ion exchange, which are taken into account in the constitutive model.

Even though the above-mentioned scholars have made a lot of contributions to the simulated acid rain test and the chemical-mechanical model, few researches have been done on the mechanical model considering the internal chemical reaction of acid rain on loess samples. This paper mainly conducts the triaxial tests of saturated loess samples under simulated acid rain conditions, and in the chemicalmechanical framework the double hardening model is formulated to consider the chemical reactions under the action of acid rain to the saturated loess samples.

\section{Influence of Simulated Acid Rain on the Mechanical Properties of Loess}

\section{Samples}

\subsection{Materials and Test Methods}

The material used here is loess samples extracted from Xi'an area of China. The intact loess is crushed into a $2 \mathrm{~mm}$ sieve to make triaxial samples. All samples are compacted in 4 layers according to the dry density of $1.7 \mathrm{~g} / \mathrm{cm}^{3}$, with the diameter of $39.1 \mathrm{~mm}$ and the height of $80 \mathrm{~mm}$. The test conditions are sulfuric acid solutions with $\mathrm{pH} 5.0,4.0$ and 3.0 , and the control group is clean water $(\mathrm{pH} 6.9)$. The above prepared specimen is put into sulfuric acid solution for vacuum suction saturation. The specimens 
are placed on a strain-controlled triaxial instrument for consolidated drained (CD) tests. The confining pressures are 50,100,200, and $400 \mathrm{kPa}$, respectively. The degree of saturation of the samples tested are more than 0.95 and the loading rate is $0.08 \mathrm{~mm} / \mathrm{min}$. Afterwards, the loess samples with different $\mathrm{pH}$ values are sprayed with metal powder on the surface after treatment, and the surface microstructure is studied by the scanning electron microscope SEM.

\subsection{Stress-Strain Relationships}

The deviatoric stress $\mathrm{q}=\sigma_{1}-\sigma_{3}$-axial strain $\varepsilon_{1}$ curves and volumetric strain $\varepsilon_{\mathrm{v}}$-axial strain $\varepsilon_{1}$ curves under different confining pressures in the consolidated drained tests of saturated loess samples are shown in Fig. 1 and Fig. 2, respectively. Fig. 1 and Fig. 2 show that (1) the loess samples present strain-hardening behavior under confining pressures ranging from 50 to $400 \mathrm{kPa}$; and (2) the loess samples contract under various confining pressures and all the samples fail by bulging. The higher the confining pressures, the higher the peak value of the deviatoric stress and volumetric contraction. During the consolidation process, the bonds between loess particles are heavily damaged under confining pressures. Thus the strength is mainly contributed by the sliding of the loess particles in the shearing process, which leads the loess samples to present strain-hardening behavior and contraction. The higher the confining pressure, the more the bonds damage of loess particles is at the end of consolidation, which cause larger slippage of loess particles in the shear process and thus a larger peak value of deviatoric stress.

The deviatoric stress $\mathrm{q}=\sigma_{1}-\sigma_{3}$-axial strain $\varepsilon_{1}$ curves and volumetric strain $\varepsilon_{\mathrm{v}}$-axial strain $\varepsilon_{1}$ curves under different acidic conditions in the consolidated drained tests of saturated loess samples are shown in Fig. 3 and Fig. 4, respectively. It can be concluded that the mechanical properties of loess 
samples are significantly affected by the $\mathrm{pH}$ value. (1) Under confining pressures ranging from 50 to $400 \mathrm{kPa}$, the deviatoric stresses of the loess samples under acidic conditions are smaller than that under clear water. (2) The volumetric contraction of the loess samples under acidic conditions is smaller than that under clear water under various confining pressures. From the molar stress circle drawn on the obtained results, the expressions of $\mathrm{c}-\mathrm{pH}$ value and $\varphi^{\prime}-\mathrm{pH}$ value are obtained as follows:

$\varphi^{\prime}$

$=-0.1923(-\lg \mathrm{s})^{2}+2.5271(-\lg \mathrm{s})$

$+18.428$

$=-0.4959(-\lg \mathrm{s})^{2}+6.1694(-\lg \mathrm{s})$

$+2.6869$

where $s$ is the concentration of sulfuric acid, $p H=-\lg s$. The equations (1) and (2) show that with the decrease of $\mathrm{pH}$ value, both $\mathrm{c}$ decreases and $\varphi^{\prime}$ decrease. Due to the action of acid rain, the loess interior is eroded, which leads to the decrease of $c$ and $\varphi^{\prime}$. Therefore, compared with clear water, the bonds of loess particles under different acidic conditions are weaker, and the loess samples is more likely to be damaged. The lower the $\mathrm{pH}$ value, the lower the peak value of the deviatoric stress, and the lower the volumetric contraction.

\subsection{SEM Images of Loess Sample under Different Acidic Conditions}

Fig. 5 shows the microstructure of loess sample after being saturated with clear water and sulfuric acid solutions of different $\mathrm{pH}$ values. The microstructure of loess sample has undergone significant changes. It can be seen from Fig. 5(a) that the soil sample is very dense and has no obvious pores under 
clear water conditions. It shows that the cementation of immersion in clean water is strong, and a higher deviatoric stress value is required to destroy. By comparing Fig. 5(b), (c), (d) and (a), it can be seen that with the decreasing $\mathrm{pH}$ value, the sulfuric acid solution corrodes the dense structure into a pore structure, so the pores gradually increase. In addition, even large pores appear, and the pore distribution is gradually uneven. Due to the increase of internal pores, the void ratio of loess sample increases, resulting in a decrease in deviatoric stress.

\section{Constitutive Model for Loess under Acid Rain Conditions}

\subsection{Constitutive Model Considering Chemical Reaction}

Complex chemical reactions will take place in the process of loess samples immersed in sulfuric acid solution. The main component of sulfuric acid solution is sulfuric acid, and calcium carbonate is involved in the reaction in loess. In this case, the main equations for chemical reaction that occurred can be simplified as follows:

$\mathrm{CaCO}_{3}+\mathrm{H}_{2} \mathrm{SO}_{4}=\mathrm{CaSO}_{4}+\mathrm{CO}_{2}$ $\uparrow+\mathrm{H}_{2} \mathrm{O}$

3)

For the macroscopic model of chemical reaction with sulfuric acid, it is considered that the loess is a porous medium material. In the chemical reaction process, the solid part of the material is formed by the precipitation of unreacted loess and the slightly water-soluble $\mathrm{CaSO}_{4}$ generated by the reaction. The condition for the reaction to occur is that the aqueous sulfuric acid solution diffuses into the unreacted 
loess through the precipitate of $\mathrm{CaSO}_{4}$ that has been formed. The aqueous sulfuric acid solution is then consumed until the chemical reaction can no longer occur. Therefore, the reaction is controlled by the diffusion of the sulfuric acid solution through the compound layer. In order to be able to take this chemical reaction into account in the constitutive equation, this paper adopts the chemical-mechanical constitutive model was proposed to describe the influence of chemical reactions on soil properties from the macroscopic level (Coussy, 1995; Ulm and Coussy, 1996). The loess consisting of skeleton and fluid is a porous medium material. The deformation of loess is considered to be caused by the irreversible behavior of the soil skeleton indicated by the plastic strain $\varepsilon^{p}$ and the hardening variable $\chi$. In addition, for the fluid phase saturated porous space of loess, the sulfuric acid solution is reactive and can react with loess. The conservation of mass of the reaction:

$$
\begin{aligned}
& =-\nabla_{X} M_{s a} \\
& +m_{\rightarrow s a}^{\circ}
\end{aligned}
$$

where $\mathrm{d} m_{m a}$ is the change in the mass of the sulfuric acid per unit of macroscopic volume. $\nabla_{X} M_{s a}$ is the external rate of sulfuric acid fluid mass supply. $m_{\rightarrow s a}^{\circ}$ is the rate of mass consumption of the sulfuric acid during the chemical reaction.

Due to the occurrence of chemical reactions, the Clausius-Duhem inequality associated with the deformable porous continuum can be derived:

$$
\geq 0
$$


where $\Phi_{t h}$ is the thermal dissipation. $\Phi_{s a}$ is the dissipation associated with the transport of the sulfuric acid.

\section{Considering the early immersion of soil in acid solution, the dissipation is mainly caused by the} irreversible skeleton evolution of loess and the chemical reaction between sulfuric acid solution and calcium carbonate, so the expression is as follows:$$
\Phi^{\prime}=\Phi_{\rightarrow s a}+\Phi_{S}
$$$$
\geq 0
$$$$
\Phi_{\rightarrow s a}=-\mu_{s a} m_{\rightarrow s a}^{\circ}
$$
$\geq 0$

where $\Phi_{\rightarrow s a}$ is the dissipation related to the chemical reaction between sulfuric acid solution and calcium carbonate, $\mu_{\mathrm{sa}}$ is the chemical potential difference. It shows the thermodynamic imbalance between the sulfuric acid solution and the chemical composition of calcium carbonate involved in the reaction. Chemical dissipation $\Phi_{\rightarrow s a}$ can be written in the equivalent form:

$\geq 0$

$$
\Phi_{\rightarrow s a}=A_{m}^{\prime} \frac{d \xi}{d t}
$$

where $A_{m}^{\prime}$ is the affinity of the chemical reaction, which is related to chemical potential difference $\mu_{s a}$. $\xi$ is the degree of chemical reaction, which is related to the mass reaction rate $m_{\rightarrow s a}^{\circ}$. The diffusion of sulfuric acid solution through the compound layer is the main mechanism to control the reaction between sulfuric acid and calcium carbonate. The chemical affinity is related to the degree of reaction, activation energy and temperature, whose expression is as follows: 
$214=k \frac{d \xi}{d t} \exp \left(\frac{E_{a}^{\prime}}{R T}\right)$

215 The dissipation associated with the skeleton is written as:

$217=\sigma: \frac{d \varepsilon}{d t}+\mu_{s a} \frac{d m_{s a}}{d t}-\mathrm{S} \frac{d T}{d t}$

$218-\frac{d \psi}{d t}$

$230=-\frac{\partial \mu_{s a}}{\partial T}$

$232=S$

$233-m_{s a} s_{s a}$ 
$235=\sigma: \frac{d \varepsilon}{d t}+p \frac{d}{d t}\left(\frac{\phi}{A}\right)-\mathrm{S}_{\mathrm{s}} \frac{d T}{d t}$

$236-\frac{d \psi_{s}}{d t}$

$239=\left[-\frac{1}{A} \nabla_{x} p+\rho_{s a}\left(f-\gamma^{s a}\right)\right]$

$243=\sigma: \frac{d \varepsilon}{d t}+p \frac{d \phi}{d t}-\mathrm{S}_{s} \frac{d T}{d t}$

$244-\frac{d \psi_{s}}{d t}$ and calcium carbonate, and the expression is written as:

$$
\Phi^{\prime}=\sigma: \frac{d \varepsilon}{d t}+\mu_{s a} \frac{d m_{s a}}{d t}-\mathrm{S} \frac{d T}{d t}-A_{m}^{\prime} \frac{d \xi}{d t}-\frac{d \psi}{d t}
$$




$$
=-\frac{\partial \psi}{\partial \xi}
$$

Alternatively, use of energy G defined by:

Formula (21) becomes:

$$
=-\frac{\partial G}{\partial \xi}
$$

$$
\sigma=\frac{\partial \mathrm{G}}{\partial \varepsilon}, S=-\frac{\partial G}{\partial T}+s_{s a} m_{s a}, \phi=\frac{m_{s a}}{\rho_{s a}}=-\frac{\partial G}{\partial p}, \zeta=-\frac{\partial G}{\partial \chi}, \quad A_{m}^{\prime}
$$

By differentiating the above equation of state, a complex equation of state can be obtained:

$270=\frac{\partial^{2} G}{\partial \varepsilon^{2}}:\left(d \varepsilon-d \varepsilon^{p}\right)+\frac{\partial^{2} G}{\partial \varepsilon \partial p} \mathrm{~d} p+\frac{\partial^{2} G}{\partial \varepsilon \partial T} d T$

$271+\frac{\partial^{2} G}{\partial \varepsilon \partial \xi} d \xi$

$$
d S=-\frac{\partial^{2} G}{\partial T^{2}} d T-\frac{\partial^{2} G}{\partial \varepsilon \partial T}:\left(d \varepsilon-d \varepsilon^{p}\right)-\frac{\partial^{2} G}{\partial T \partial p} d p-\frac{\partial^{2} G}{\partial T \partial \xi} d \xi
$$

In the process of reaction between sulfuric acid solution and remolded loess, we believe that the 
where $D=\frac{\partial^{2} G}{\partial \varepsilon^{2}}$ is the elastic stiffness tensor, $a=D^{-1}: \frac{\partial^{2} G}{\partial \varepsilon \partial \xi}$ is the chemical expansion coefficient tensor. $b=D^{-1}: \frac{\partial^{2} G}{\partial \varepsilon \partial p}$ is the Biot's tangent tensor. For the isotropic case, $a=\beta_{s} \mathbf{1}$, Equation (25) becomes:

$$
d \varepsilon-d \varepsilon^{p}=\frac{1}{3 G} d \sigma_{s}+\left(\frac{1}{K} d \sigma_{m}\right.
$$

where $\sigma_{m}^{\prime}=\frac{1}{3}\left(\sigma_{1}+2 \sigma_{3}\right), \sigma_{s}=\left(\frac{3}{2} s_{i j} s_{j i}\right)^{1 / 2}=\sigma_{1}-\sigma_{3}, \sigma_{m}=\sigma_{m}^{\prime}-p$. The axial stress, confining

In the formula, $F(\sigma, p, \zeta)$ is the loading function. When the loading point remains constant at the boundary of $C_{E}$ in the elastic domain $(F=d F=0)$, the plastic variable $\varepsilon^{p}$ and $\chi$ will evolve. In a variable $\chi(\zeta=\zeta(\chi))$, but to the loess dipped in acid rain has also been chemical hardening phenomenon. 
301 With regard to the development of plastic variables, the hardening law and flow law are written:

$303=d \lambda \frac{\partial g(\sigma, p, \zeta)}{\partial \sigma}$

$$
d F=0 \Leftrightarrow \frac{\partial F}{\partial \zeta} \frac{\partial \zeta(\chi, \xi)}{\partial \chi} d \chi=-d_{\chi} F=-d \lambda H
$$

obtained:

$$
d \lambda=\frac{d_{\chi} F}{H}=\frac{1}{H}\left(\frac{\partial F}{\partial \sigma}: d \sigma+\frac{\partial F}{\partial p} d p+\frac{\partial F}{\partial \zeta} \frac{\partial \zeta}{\partial \xi} d \xi\right)
$$

$316=-\frac{\partial F}{\partial \zeta} \frac{\partial \zeta}{\partial \chi} \frac{\partial g(\sigma, p, \zeta)}{\partial \zeta}$

loess can be obtained:

$$
\varphi d t=d \lambda\left(\sigma: \frac{\partial g}{\partial \sigma}+p \frac{\partial g}{\partial p}+\zeta \frac{\partial g}{\partial \zeta}\right) \geq 0, F=d F=0
$$



increment $\mathrm{d} \varepsilon^{p}$ is represented by thermodynamics $\frac{\partial g(\sigma, p, \zeta)}{\partial \sigma}$ and $\frac{\partial g(\sigma, p, \zeta)}{\partial p}$, and $d \chi$ is represented by thermodynamics $\frac{\partial g(\sigma, p, \zeta)}{\partial \zeta}$. Furthermore, the elastic domain develops and changes because of the hardening force is affected by the degree of chemical reaction, even if there is no plastic evolution in the loess specimen $(d \lambda=0)$, the hardening variable $\chi$ remained unchanged in $\mathrm{d} t$ duration. The degree of chemical reaction $\xi$ is defined according to physical chemistry as:

$327=\frac{s V-n_{B}(0)}{v_{B}}$

where $s$ is the concentration of sulfuric acid solution; $v_{B}$ is the measurement coefficient of the above formula becomes:

$335=\frac{\left(s-s_{0}\right) V}{v_{B}}$

$339=\frac{\xi}{N_{0}}$ 

have $\varepsilon_{s}=\left(\frac{2}{3} e_{i j} e_{j i}\right)^{1 / 2}=\frac{2}{3}\left(\varepsilon_{1}-\varepsilon_{3}\right), \varepsilon_{\mathrm{v}}=\varepsilon_{1}+2 \varepsilon_{3}$. Strain deviation tensor is denoted by $e_{i j} ;$ the axial strain, shear strain and radial strain are respectively denoted by $\varepsilon_{1}, \varepsilon_{s}$ and $\varepsilon_{3} . \sigma_{m}$ is the effective stress, $\sigma_{m}=\sigma_{m}^{\prime}-p$.When the loess is under triaxial compression: the current elastic interval is written as:

where $\zeta_{1}\left(\varepsilon_{s}^{p}, \xi\right), \zeta_{2}\left(\varepsilon_{v}^{p}, \xi\right)$ are expressed as a hardening parameter; $\mathrm{n}$ is the parameter related to the written as:

$359=\alpha_{c}(\xi) \alpha_{m 0}[1$ 
$363 \quad \zeta_{2}\left(\varepsilon_{v}^{p}, \xi\right)=\left[1-a_{3}\left(\frac{\xi}{N_{0}}\right)\right] \sigma_{c 0} \exp \left(\beta \varepsilon_{v}^{p}\right)$

364

$365=\alpha_{0}$

$366+N_{s 0} \frac{\xi}{N_{0}}$

367 where the material parameters are $\alpha_{m 0}, a_{1}, a_{2}$ and $c_{3}$; and the reference pressure is $\sigma_{c 0}$.

368 Using the associated flow rule, the yield function $\mathrm{F}$ is consistent with the plastic potential function

$369 g$, namely $F=g$. We can get the $d \varepsilon_{v}^{p}$ and $d \varepsilon_{s}^{p}$ :

370

$d \varepsilon_{v}^{p}$

$371=d \lambda$

$372 \frac{\partial g}{\partial \sigma_{m}}$

$373 \quad$ (42-a)

$375=d \lambda$

$376 \quad \frac{\partial g}{\partial \sigma_{s}}$

377

(42-b)

378 Meeting the consistency condition, the expression of $H$ and $d \lambda$ are written as:

$$
d \lambda=\frac{1}{H}\left[\frac{\partial F}{\partial \sigma_{m}} d \sigma_{m}+\frac{\partial F}{\partial \sigma_{s}} d \sigma_{s}+\left(\frac{\partial F}{\partial \zeta_{1}} \frac{\partial \zeta_{1}}{\partial \xi}\right.\right.
$$

380

$$
\left.\left.+\frac{\partial F}{\partial \zeta_{2}} \frac{\partial \zeta_{2}}{\partial \xi}\right) d \xi\right]
$$

381

$382=-\frac{\partial F}{\partial \zeta_{1}} \frac{\partial \zeta_{1}}{\partial \chi_{1}} \frac{d \chi_{1}}{d \lambda}$

$383-\frac{\partial F}{\partial \zeta_{2}} \frac{\partial \zeta_{2}}{\partial \chi_{2}} \frac{d \chi_{2}}{d \lambda}$ 
$386=-\frac{\partial F}{\partial \zeta_{1}} \frac{\partial \zeta_{1}}{\partial \varepsilon_{s}^{p}} \frac{\partial F}{\partial \sigma_{s}}$

$387-\frac{\partial F}{\partial \zeta_{2}} \frac{\partial \zeta_{2}}{\partial \varepsilon_{v}^{p}} \frac{\partial F}{\partial \sigma_{m}}$

388 where

$\frac{\partial F}{\partial \sigma_{m}}=\frac{1-(1+n)\left(\frac{\eta}{\zeta_{1}}\right)^{n}}{\left(1-\left(\frac{\eta}{\zeta_{1}}\right)^{n}\right)^{2}}, \frac{\partial F}{\partial \sigma_{s}}=\frac{n\left(\frac{\eta}{\zeta_{1}}\right)^{n-1}}{\zeta_{1}\left(1-\left(\frac{\eta}{\zeta_{1}}\right)^{n}\right)^{2}}, \frac{\partial \zeta_{1}}{\partial \xi}=\alpha_{m 0}\left[1-a_{1} \exp \left(-\frac{\varepsilon_{s}^{p}}{a_{2}}\right)\right] \frac{N_{s 0}}{N_{0}}$

390

$\frac{\partial \zeta_{2}}{\partial \xi}=-\sigma_{c 0} \exp \left(\beta \varepsilon_{v}^{p}\right) \frac{a_{3}}{N_{0}}, \frac{\partial F}{\partial \zeta_{1}}=\frac{-n \sigma_{m} \eta^{n}}{\zeta_{1}^{n+1}\left[1-\left(\frac{\eta}{\zeta_{1}}\right)^{n}\right]^{2}}, \frac{\partial F}{\partial \zeta_{2}}=-1, \frac{\partial \zeta_{2}}{\partial \varepsilon_{v}^{p}}=\beta \zeta_{2}$.

391

$\frac{\partial \zeta_{1}}{\partial \varepsilon_{s}^{p}}=\frac{1}{a_{2}}\left(\zeta_{1}-\alpha_{c}(\xi) \alpha_{m 0}\right)$

Hence, the shear and volumetric strain increments composed of elasticity and plasticity:

$$
d \varepsilon_{v}=d \varepsilon_{v}^{E}+d \varepsilon_{v}^{p}
$$

$=A_{1} d \sigma_{m}+A_{2} d \sigma_{s}$

395

$+A_{3} d \xi$

396

399

where

400

$A_{1}=\frac{1}{K}+\frac{1}{H} \frac{\partial F}{\partial \sigma_{m}} \frac{\partial F}{\partial \sigma_{m}}, A_{2}=\frac{1}{H} \frac{\partial F}{\partial \sigma_{m}} \frac{\partial F}{\partial \sigma_{s}}, A_{3}=\frac{1}{H}\left(\frac{\partial F}{\partial \zeta_{1}} \frac{\partial \zeta_{1}}{\partial \xi}+\frac{\partial F}{\partial \zeta_{2}} \frac{\partial \zeta_{2}}{\partial \xi}\right) \frac{\partial F}{\partial \sigma_{m}}-\beta_{s}$

401

$B_{1}=\frac{1}{H} \frac{\partial F}{\partial \sigma_{m}} \frac{\partial f}{\partial \sigma_{s}}, B_{2}=\frac{1}{3 G}+\frac{1}{H} \frac{\partial F}{\partial \sigma_{s}} \frac{\partial F}{\partial \sigma_{s}}, B_{3}=\frac{1}{H}\left(\frac{\partial F}{\partial \zeta_{1}} \frac{\partial \zeta_{1}}{\partial \xi}+\frac{\partial F}{\partial \zeta_{2}} \frac{\partial \zeta_{2}}{\partial \xi}\right) \frac{\partial F}{\partial \sigma_{s}}$

\subsection{Model Validation}


The parameters of consolidated drained tests are as follows: $E=E_{0}\left(\frac{\sigma_{\mathrm{c} 0}}{\mathrm{P}_{\mathrm{a}}}\right)^{m}, E_{0}=$ $-48.177(-\lg s)^{2}+1582.1(-\lg s)+293.47, m=-0.0196(-\lg s)+0.8246 . \sigma_{c 0}$ is the reference pressure when $\varepsilon_{v}^{p}=0$. In this paper, the confining pressure of the conventional triaxial consolidated drained shear tests under the corresponding conditions is $50,100,200$ and $400 \mathrm{kPa}$, respectively. Standard atmospheric pressure is represented by $P_{a}$. The values of $\mathrm{K}$ and $\mathrm{G}$ are determined by $K=\frac{E}{3(1-2 v)}$ and $G=\frac{E}{2(1+v)}$, Poisson's ratio $v=0.2$. The initial pore ratio is represented by $e_{0}, e_{0}=0.712 . \lambda$ represents the slope of the isobaric consolidation curve, and $\kappa$ represents the slope of the rebound curve. It is available in the $v-\ln p$ plane: $\lambda=0.088, \kappa=0.008 . \beta=\frac{1+e_{0}}{\lambda-\kappa}=$ 21.4, $n=1.4, \alpha_{m 0}$ is a model parameter related to $\mathrm{n}$ and effective internal friction Angle $\varphi^{\prime} . \varphi^{\prime}=$ $-0.1923(-\lg s)^{2}+2.5271(-\lg s)+18.428$. The expression is as follows:

$$
=1.25 \sqrt[n]{1+n} \frac{6 \sin \varphi^{\prime}}{3-\sin \varphi^{\prime}}
$$

According to the value of the effective internal friction angle under different acidic conditions, the different values of $\alpha_{m 0}$ can be obtained. $N_{s 0}=0.0002, a_{3}=0.001, \beta_{s}=-0.001, \alpha_{0}=$ $1.0043\left(\frac{\sigma_{c 0}}{P_{a}}\right)^{-0.131}, a_{1}=0.0003(-\lg s)^{2}-0.0122(-\lg s)+0.9681, a_{2}=-0.0008(-\lg s)^{2}+$ 0.0102(- $\lg s)-0.0379$. As can be seen from Fig. 6 and Fig. 7. The results show that the deviatoric stress-axial strain curves and volumetric strain-axial strain curves of saturated loess can be simulated by a double-hardening model considering the influence of concentration. The simulated results of the model under all confining pressures present strain-hardening behavior and contract, which is consistent with the tested results of loess and whose peak value is very close to the tested results. For the simulated results, the higher the confining pressures, the higher the peak of the deviatoric stress and volumetric contract. The simulated results at different $\mathrm{pH}$ values can be the same as the tested results of saturated loess. With 
the decrease of $\mathrm{pH}$ values, the peak of the simulated deviatoric stress and volumetric contract decrease. Although the simulated values are slightly different from the experimental results, the double hardening model can better reflect the deformation behavior of saturated loess.

\subsection{Parameter Sensitivity Analysis}

Fig. 8-14 shows the calculated results when the model parameters change when the acidic condition is pH 5 and the confining pressure is $200 \mathrm{kPa}$, including $a_{1}, a_{2}, a_{3}, \alpha_{0}, \beta_{s}, n$ and $N_{s 0}$. The model calculated results can reflect the main mechanical behavior of loess. From the deviatoric stress-axial strain curves, it show that with the decrease of $N_{s 0}$ and $a_{3}$, the loess samples present strain hardening behavior; With the decrease of $a_{1}, \beta_{s}$ and $n$, the loess samples behave strain softening slightly to strain hardening, and the deviatoric stress peak value decreases; While the reduction of $a_{2}$ and $\alpha_{0}$, the loess samples behave strain hardening slightly to strain softening. For volumetric strain change, with the decrease of $a_{1}, a_{2}, \beta_{s}$ and $n$, the loess samples contract more heavily. With the decrease of $\alpha_{0}, a_{3}$, and $N_{s 0}$, the loess samples dilate more heavily. On the whole, the values of $a_{1}, a_{2}$ and $a_{3}$ have the greatest impact on the simulation results, that is, the most sensitive. The value of $\alpha_{0}$ and $N_{s 0}$ have the second effect, and $\beta_{s}$ and $n$ have the least effect.

\section{Conclusions}

1. By performing the $\mathrm{CD}$ experiments of acid rain on loess samples, we found that with the increase of acid rain concentration, the peak of the deviatoric stress decreases, and the samples contracts less. Through SEM analysis of the microstructure, it is found that the cementation failure caused by acid rain erosion on loess is the reason for the reduction of strength. 

conditions is proposed. The chemical reaction degree of sulfuric acid and calcium carbonate is taken into account in the framework and the elastoplastic constitutive relation is established.

3. Different $\mathrm{pH}$ values are introduced into the double hardening model through the degree of chemical reaction, and the mechanics and deformation behavior of the loess under different acid rain conditions can be well simulated by the proposed model.

Consent to Participate Since this study did not recruit any human subjects, this section does not apply. previously published material, this section does not apply.

Ethical approval Since this study did not recruit any human and/or animal subjects, this section does not apply. corresponding author on reasonable request.

Acknowledgments We thank the anonymous reviewers for their comments on our paper.

Authors' contributions All the authors have designed this study equally. XY collected, analyzed and interpreted the results of the study. And XY drafted the initial manuscript. YY helped XY do the experiment. EL and BD have revised and restructured the manuscript.

Funding This research was supported by National Science Foundation of China (Grant No. 41790431)

\section{References}


Boukpeti N, Charlier R, Hueckel T (2004) Modelling contamination of clays. Elsevier Geo-

Engineering Book Series 2:523-528. DOI: 10.1016/S1571-9960(04)80093-4

Bunger AP (2010) The mandel-cryer effect in chemoporoelasticity. .International Journal for Numerical and Analytical Methods in Geomechanics 34(14):1479-1511. DOI: http://orcid.org/0000-0002-0696-

7066

Bakhshipour Z, Asadi A, Huat BBK, Sridharan A (2016) Effect of Acid Rain on Geotechnical

Properties of Residual Soils. Soils and Foundations 56(6): 1008-1020. DOI:

10.1016/j.sandf.2016.11.006

Bakhshipour Z, Asadi A., Huat BBK, Sridharan A (2016) Long-Term Intruding Effects of Acid Rain on Engineering Properties of Primary and Secondary Kaolinite Clays. International Journal of Geosynthetics and Ground Engineering 2(3). DOI: 10.1007/s40891-016-0059-1

Buscarnera G, Das A (2016) Chemo-mechanics of cemented granular solids subjected to precipitation and dissolution of mineral species. International Journal for Numerical and Analytical Methods in Geomechanics 40(9). DOI: 10.1002/nag.2486

Bakhshipour Z, Asadi A, Sridharan A, et al. (2017) Acid Rain Intrusion Effects on The Compressibility Behaviour of Residual Soils. Journal of Environmental Geotechnics 1-38. DOI: 10.1680/jenge.15.00081 Coussy O (1995) Mechanics of Porous Continua. John Wiley and Sons, Chichester, U.K.

Coussy O, Ulm F (1996) Creep and plasticity due to chemo-mechanical couplings. Archive of Applied Mechanics 66:523-535. DOI: 10.1007/BF00808142

Coussy O (2004) Poromechanics, John Wiley \& Sons, Ltd. 
Chavali, Ponnapureddy (2018) Swelling and compressibility characteristics of bentonite and kaolin clay subjected to inorganic acid contamination. International Journal of Geotechnical Engineering 12(5). DOI: $10.1080 / 19386362.2017 .1299418$

Detournay E, Sarout J, Tan C, Caurel J (2005) Chemoporoelastic parameter identification of a reactive shale. vol. 125 of Solid Mechanics and its Applications 125-132.

Ding WX, Feng XT (2009) Damage effect and fracture criterion of rock with multi-preexisting cracks under chemical erosion. Chinese Journal of Geotechnical Engineering 31(6): 899-904.

Gajo A, Loret B, Hueckel T (2002) Electro-chemo-mechanical couplings in saturated porous media: elastic-plastic behaviour of heteroionic expansive clays. International Journal of Solids and Structures 39(16):4327-4362. DOI: 10.1016/S0020-7683(02)00231-7

Gawin D, Pesavento F, Schrefler BA (2006) Hygro-thermo-chemo-mechanical modelling of concrete at early ages and beyond. Part I: hydration and hygro-thermal phenomena. International Journal for Numerical Methods in Engineering 67 (3):299-331. DOI: 10.1002/nme.1615

Guimaraes LDN, Gens A, Olivella S (2007) Coupled thermo-hydro-mechanical and chemical analysis of expansive clay subjected to heating and hydration. Transport in Porous Media 66(3):341-372. DOI: $10.1007 / \mathrm{s} 11242-006-0014-\mathrm{z}$

Gratchev I, Towhata I (2011) Compressibility of natural soils subjected to long-term acidic contamination. Environmental Earth Sciences 64(1). DOI: 10.1007/s12665-010-0838-2

Gratchev I, Towhata I (2016) Compressibility of soils containing kaolinite in acidic environments. KSCE Journal of Civil Engineering 20(2). DOI: 10.1007/s12205-015-0141-6 
Hueckel T (1997) Chemo-plasticity of clays subjected to stress and flow of a single contaminant. International Journal for Numerical and Analytical Methods in Geomechanics 21(1):43-72. DOI: 10.1002/(SICI)1096-9853(199701)21:1<43::AID-NAG858>3.3.CO;2-T

Han TL, Chen YS, Shi JP, et al. (2013) Experimental study of mechanical characteristics of sandstone subjected to hydrochemical erosion. Chinese Journal of Rock Mechanics and Engineering 32(S2): $3064-$ 3072.

Hassanlourad M, Khatami MH, Ahmadi MM (2017) Effects of sulphuric acid pollutant on the shear behaviour and strength of sandy soil and sand mixed with bentonite clay. International Journal of Geotechnical Engineering 11(2). DOI: 10.1080/19386362.2016.1193662

Huang Z, Zeng W, Wu Y, Li SJ, Gu QX, Zhao K(2021) Effects of temperature and acid solution on the physical and tensile mechanical properties of red sandstones. Environmental Science and Pollution Research. DOI: 10.1007/s11356-020-11866-X

Jendele L, Smilauer V, Cervenka J (2014) Multiscale hydro-thermo-mechanical model for early-age and mature concrete structures. Advances in Engineering Software 72 (2):134-146. DOI: 10.1016/j.advengsoft.2013.05.002

Jalali M, Naderi E (2012) The Impact of Acid Rain on Phosphorus Leaching from a Sandy Loam Calcareous Soil of Western Iran. Environmental Earth Sciences 66(1):311-317. DOI: 10.1007/s12665011-1240-4

Koupai JA, Fatahizadeh M, Mosaddeghi MR (2020) Effect of pore water pH on mechanical properties of clay soil. Bulletin of Engineering Geology and the Environment: The official journal of the IAEG 79(1). DOI: 10.1007/s10064-019-01611-1 
526

527

Kyokawa H, Ohno S, Kobayashi I (2020) A method for extending a general constitutive model to consider the electro-chemo-mechanical phenomena of mineral crystals in expansive soils. International Journal for Numerical and Analytical Methods in Geomechanics 44(6). DOI: 10.1002/nag.3026 Luzio GD, Cusatis G (2009) Hygro-thermo-chemical modeling of high performance concrete. I: theory. Cement and Concrete Composites 31 (5):301-308. DOI: 10.1016/j.cemconcomp.2009.02.015

Liu EL, Xing H (2009) A double hardening thermo-mechanical constitutive model for overconsolidated clays. Acta Geotechnica (4): 1-6. DOI: 10.1007/s11440-008-0053-4

Lei XQ, Wong H, Fabbri A, Limam A, Cheng YM (2016) A chemo-elastic-plastic model for unsaturated expansive clays. International Journal of Solids and Structures 88-89. DOI: 10.1016/j.ijsolstr.2016.01.008

Liu, EL, Lai YM, Wong H, Feng JL (2018) An elastoplastic model for saturated freezing soils based on thermo-poromechanics. International Journal of Plasticity 107:246-285. DOI: 10.1016/j.ijplas.2018.04.007

Liu H, He JT, Zhao Q, Wang TX, Guo CY (2020) Experimental study on the evolution law of seepage microscopic characteristics of undisturbed loess polluted by acid. Rock and soil mechanics 41(03):765772.

Liu EL, Lai YM (2020) Thermo-poromechanics-based viscoplastic damage constitutive model for saturated frozen soil. International Journal of Plasticity 128:102683. DOI: 10.1016/j.ijplas.2020.102683 Liang CJ, Ma YJ, Li LR(2020) Comparison of plasma membrane H + -ATPase response to acid rain stress between rice and soybean. Environmental Science and Pollution Research 27(6). DOI: http://orcid.org/0000-0001-7704-4309 
Moyne C, Murad MA (2002) Electro-chemo-mechanical couplings in swelling clays derived from a micro/macro-homogenization procedure. International Journal of Solids and Structures 39(25):61596190. DOI: $10.1016 / \mathrm{S} 0020-7683(02) 00461-4$

Martinelli E, Koenders EAB, Caggiano A (2013) A numerical recipe for modelling hydration and heat flow in hardening concrete. Cement and Concrete Composites 40 (2): 48-58. DOI: 10.1016/j.cemconcomp.2013.04.004

Nova R, Castellanza R, Tamagnini C (2003) A constitutive model for bonded geomaterials subject to mechanical and/or chemical degradation. International Journal for Numerical and Analytical Methods in Geomechanics 27(9):705-732. DOI: 10.1002/nag.294

Sherwood J (1993) Biot poroelasticity of a chemically activeshale. Proceedings of the Royal Society:

Mathematical and Physical Sciences 440(1909):365-377. DOI: 10.1098/rspa.1993.0021

Shen ZJ (1995) Double hardening model of clay. Rock and Soil Mechanics 01:1-8.

Sarout J, Detournay E (2011) Chemoporoelastic analysis and experimental validation of the pore pressure transmission test for reactive shales. International Journal of Rock Mechanics and Mining Sciences 48(5):759-772. DOI: 10.1016/j.ijrmms.2011.04.009

Sarkar G, Islam R, Alamgir M, et al. (2012) Effect of Acid Rain on Geotechnical Properties of Composite Fine-grained Soil. International Journal of Applied Science \& Engineering Research 1(1):64-73. DOI: 10.6088/ijaser.0020101007

Shen WQ, Shao JF (2016) An incremental micro-macro model for porous geomaterials with double porosity and inclusion. International Journal of Plasticity 83:37-54. DOI: 10.1016/j.ijplas.2016.04.002 
Song XY, Menon S (2019) Modeling of chemo-hydromechanical behavior of unsaturated porous media: a nonlocal approach based on integral equations. Acta Geotechnica 14(3). DOI: 10.1007/s11440-0180679-9

Thomas H, Cleall P (1999) Inclusion of expansive clay behavior in coupled thermo hydraulic mechanical models. Engineering Geology 54(1):93-108. DOI: 10.1016/S0013-7952(99)00065-4

Ulm F, Coussy O, (1998) Couplings in early-age concrete: from material modeling to structural design. International Journal of Solids and Structures 35 (31): 4295-4311. DOI: 10.1016/S0020-7683(97)00317-

\section{X}

Wang M, Tang Y, Anderson CWN, Jeyakumar P, Yang JY (2018) Correction to: Effect of simulated acid rain on fluorine mobility and the bacterial community of phosphogypsum. Environmental Science and Pollution Research 25(23).DOI: http://orcid.org/0000-0002-9841-8645

Xu J, Wu H, Cheng LZ, et al. (2012) Experimental study of shearing failure properties of sandstone under acidic conditions. Chinese Journal of Rock Mechanics and Engineering 31(S2): 3897-3903.

Yao YP, Hou W, Zhou AN (2009) UH model: Three dimensional unified hardening model for overconsolidated clays. Geotechnique 59(5), 451-469.

Zhao Y, Cui P, Hu LB (2009) Relation Between Evolution of Clay Shear Strength and Landslide Induced by Acid Rain-Taking Landslides in Three Gorges Reservoir Area for Example. Journal of Rock Mechanics and Geotechnical Engineering 28(3): 576-582.

Zhang S, Leng W, Zhang F, Xiong Y (2012) A simple thermo-elastoplastic model for geomaterials. International Journal of Plasticity 34, 93-113. DOI: 10.1016/j.ijplas.2012.01.011

Zhang Z (2017) A thermodynamics-based theory for the thermos-poro-mechanical modeling of saturated clay. International Journal of Plasticity 92, 164-185. 
589 Zhu H, Wu CF, Wang J, Zhang XM (2018) The effect of simulated acid rain on the stabilization of 590 cadmium in contaminated agricultural soils treated with stabilizing agents. Environmental Science and 591 Pollution Research 25(18). DOI: 10.1007/s11356-018-1929-y

592 Zhao XY, Li KP, Li X, et al. (2019) Experimental Study on Mechanism of Acid Rain-induced Slide of 593 Gabbro Rock Slope. Journal of Engineering Geology 27(1): 152-161. DOI: 10.13544/j.cnki.jeg.2018$594 \quad 458$ 


\section{Lists of Figures and Tables}

597 Fig. 1 Deviatoric stress and axial strain curves of loess samples under different confining pressures (CD).

598 Fig. 2 Volumetric strain and axial strain curves of loess samples under different confining pressures (CD).

599 Fig. 3 Deviatoric stress and axial strain curves of loess samples under different values of pH (CD).

600 Fig. 4 Volumetric strain and axial strain curves of loess under different pH (CD).

601 Fig. 5 SEM micrographs of loess samples under acid rain conditions.

602 Fig. 6 Deviatoric stress and axial strain for tests and simulations (CD).

603 Fig. 7 Volumetric strain and axial strain for tests and simulations (CD).

604 Fig. 8 Simulated results with varying $\alpha_{0}$

605 Fig. 9 Simulated results with varying $a_{1}$

606 Fig. 10 Simulated results with varying $a_{2}$

607 Fig. 11 Simulated results with varying $a_{3}$

608 Fig. 12 Simulated results with varying $n$

609 Fig. 13 Simulated results with varying $\beta_{s}$

610 Fig. 14 Simulated results with varying $N_{s 0}$

611

612 
Figures

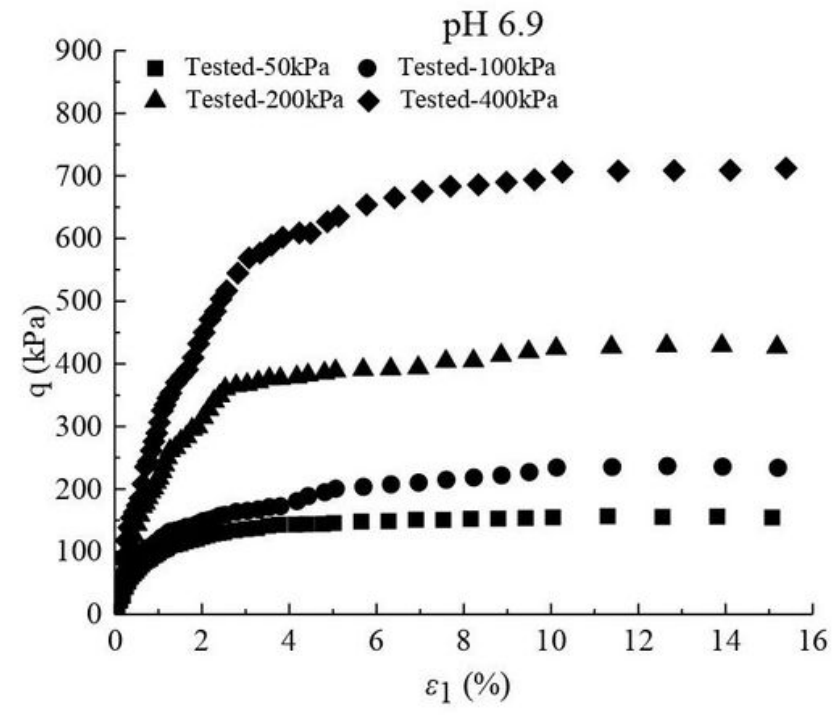

(a) $\mathrm{pH} 6.9$

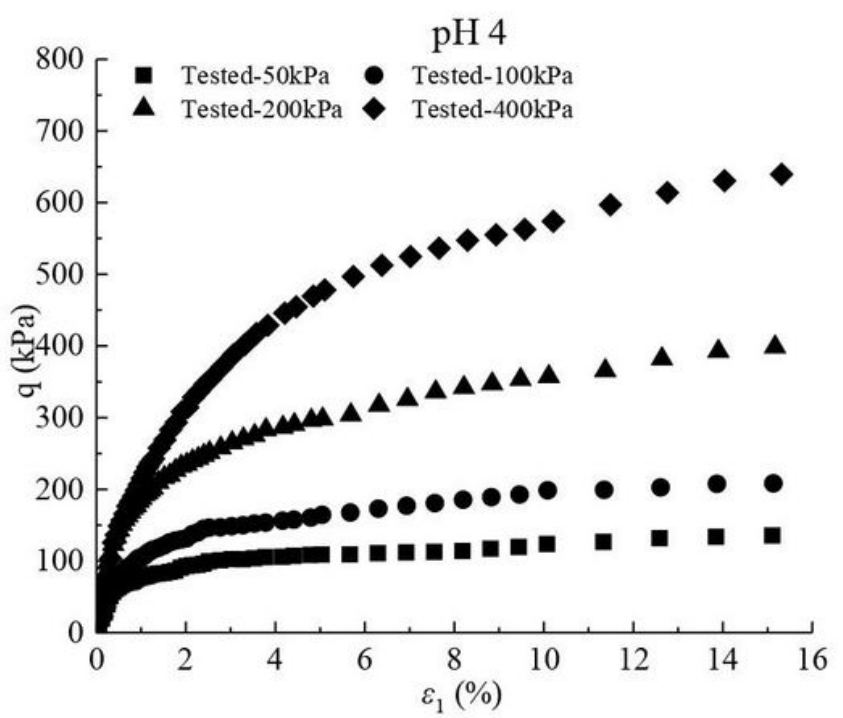

(c) $\mathrm{pH} 4$

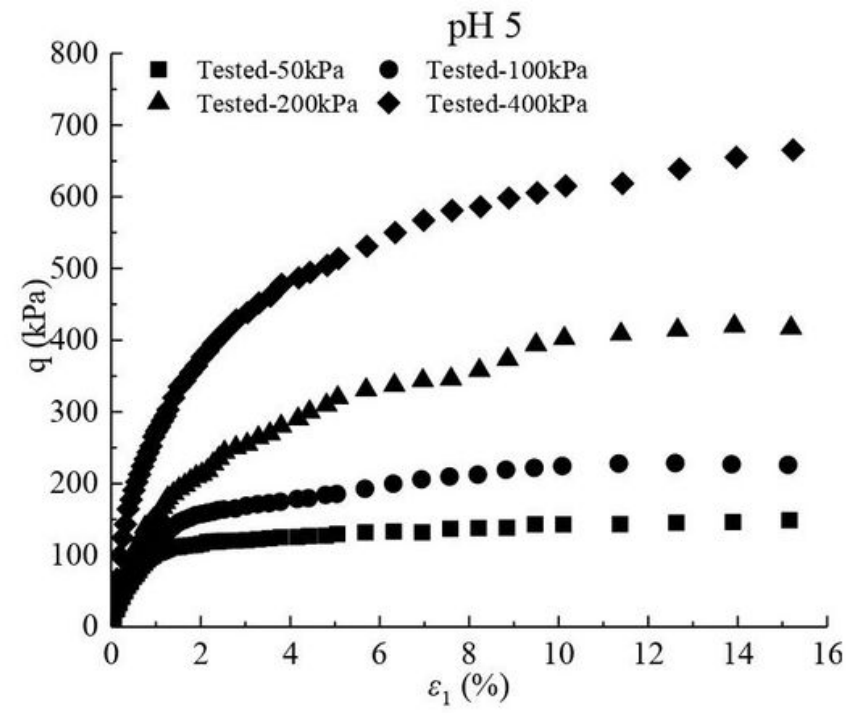

(b) $\mathrm{pH} 5$

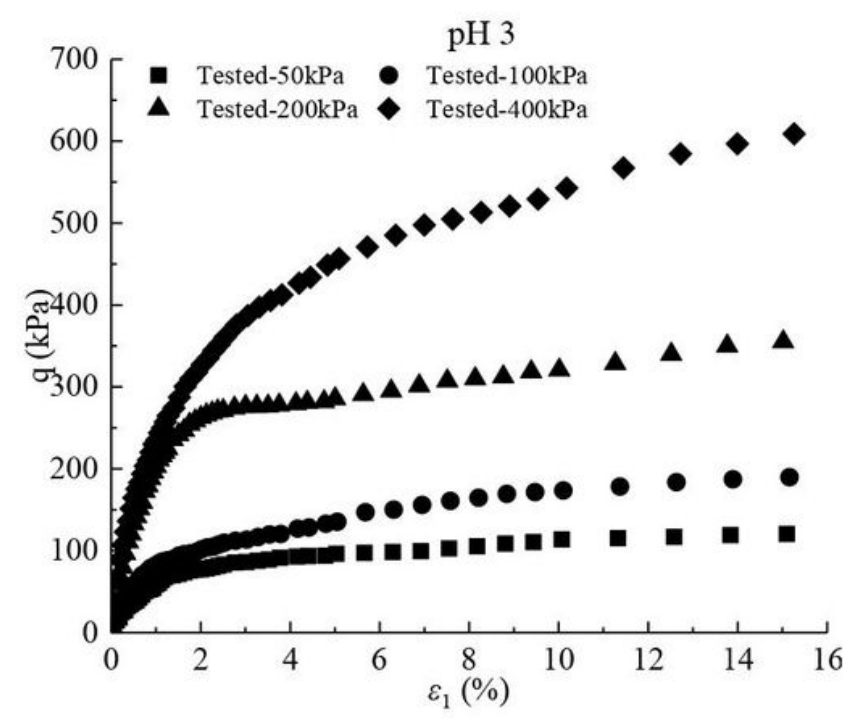

(d) $\mathrm{pH} 3$

\section{Figure 1}

Deviatoric stress and axial strain curves of loess samples under different confining pressures (CD). 


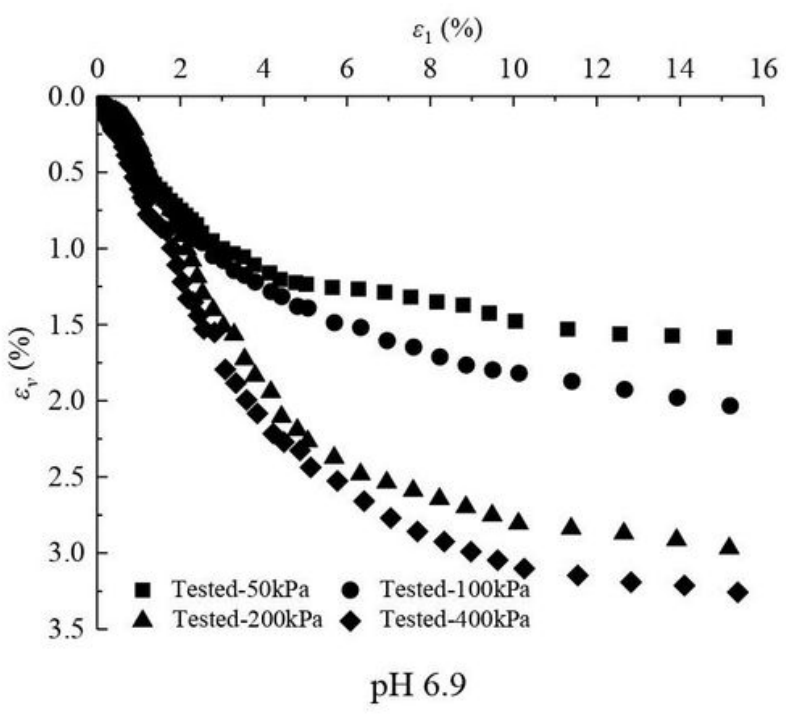

(a) $\mathrm{pH} 6.9$

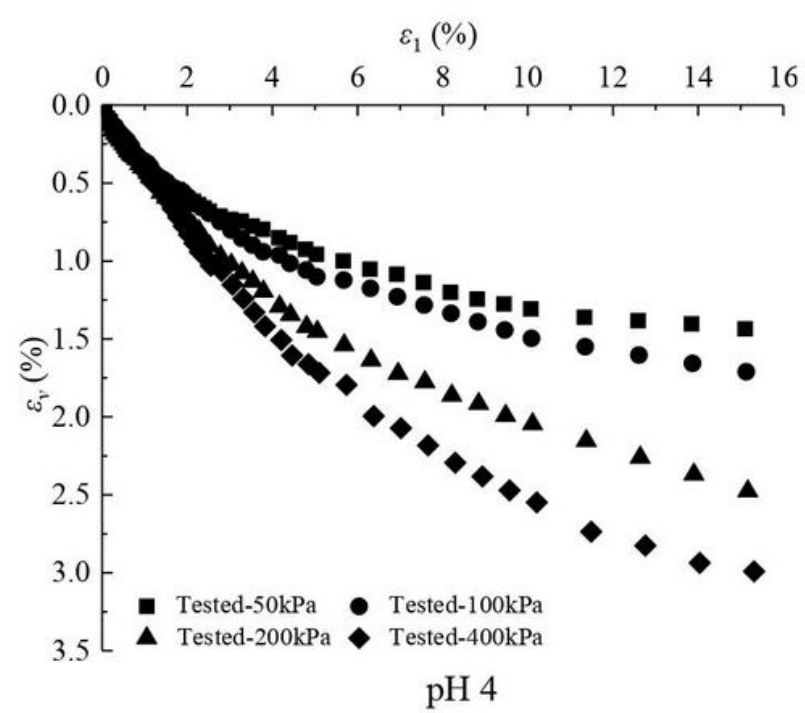

(c) $\mathrm{pH} 4$

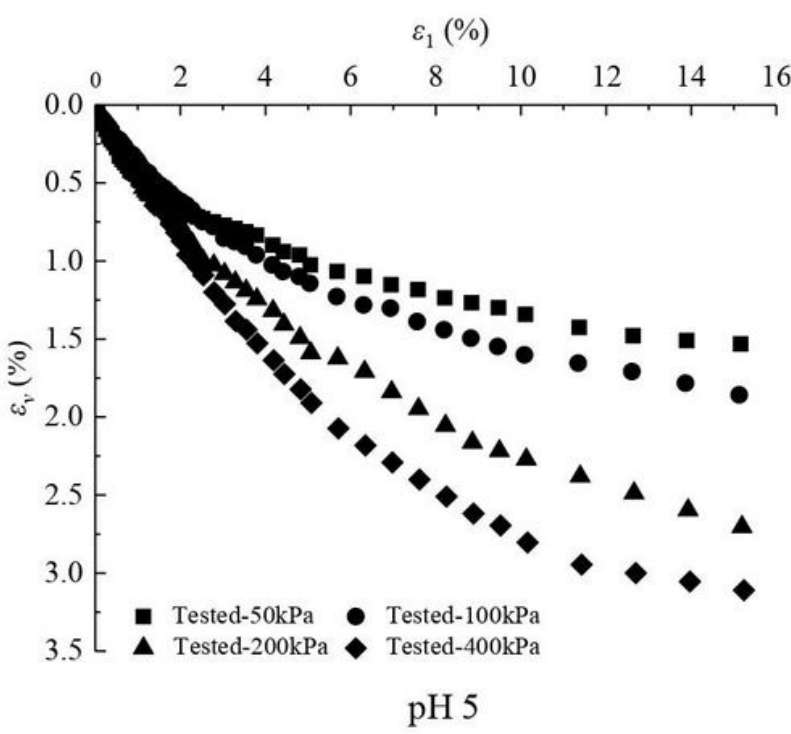

(b) $\mathrm{pH} 5$

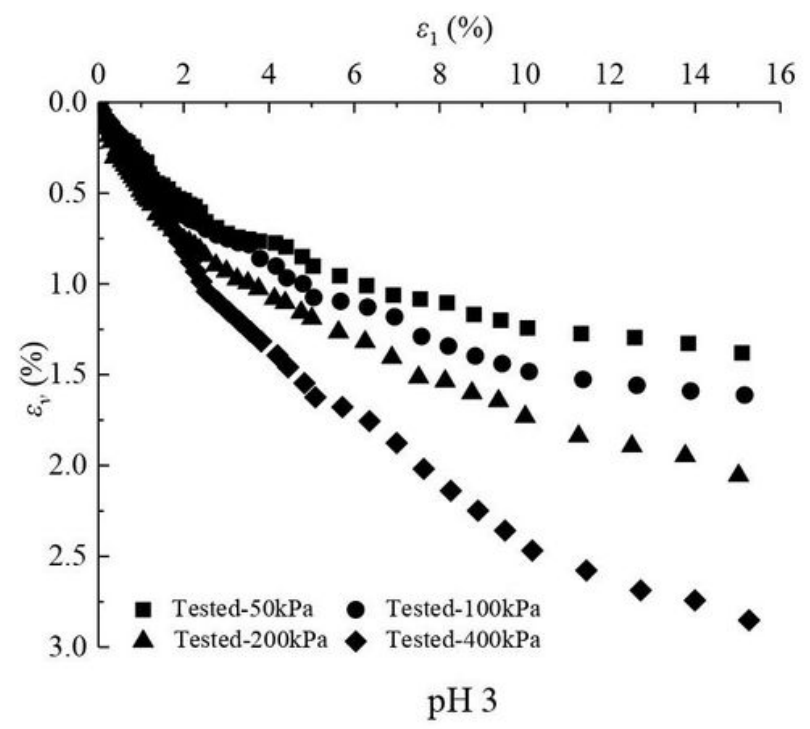

Figure 2

Volumetric strain and axial strain curves of loess samples under different confining pressures (CD). 


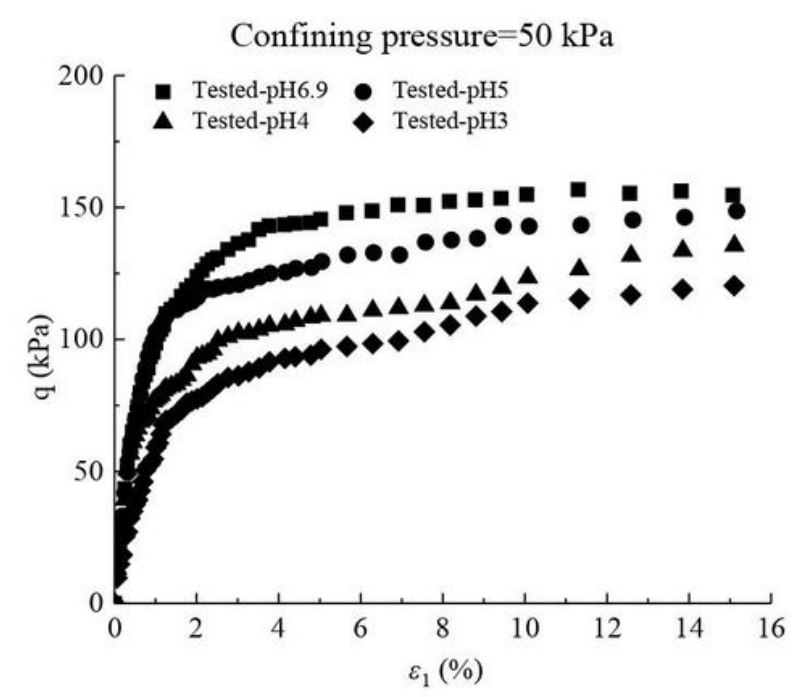

(a) Confining pressure $=50 \mathrm{kPa}$

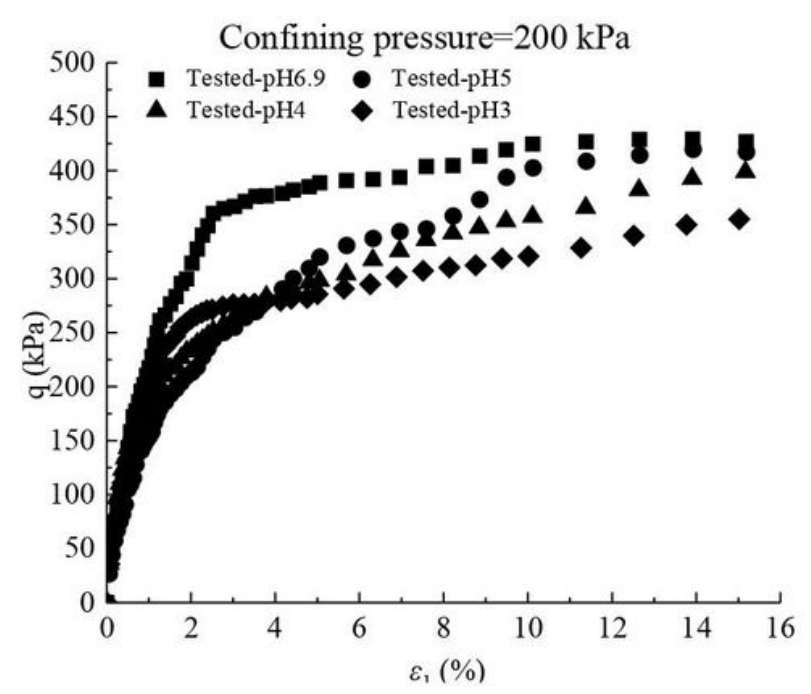

(c) Confining pressure $=200 \mathrm{kPa}$

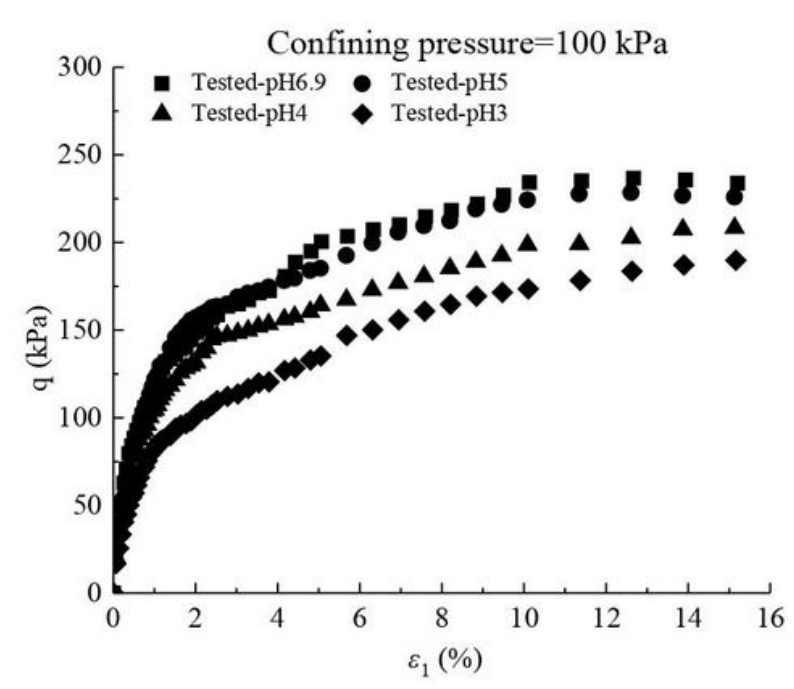

(b) Confining pressure $=100 \mathrm{kPa}$

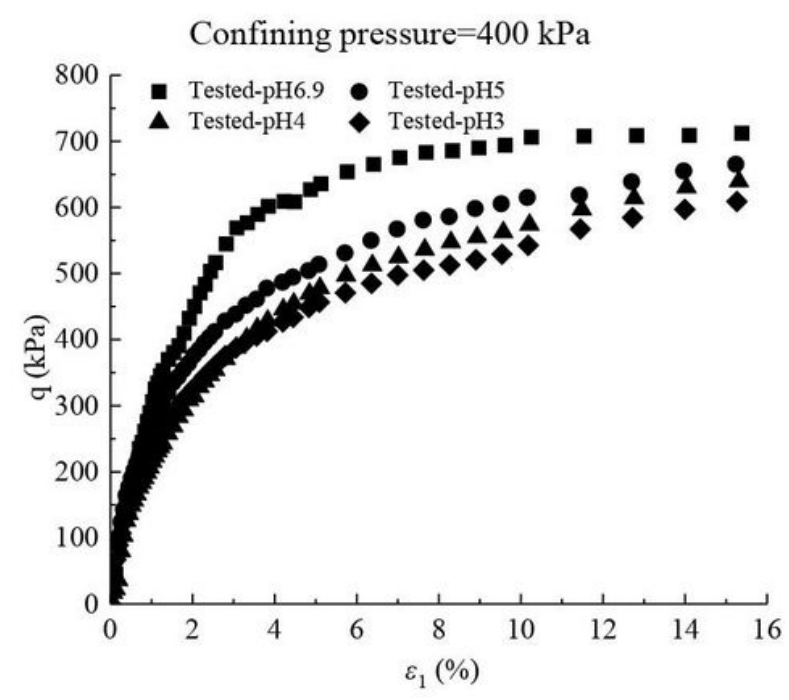

(d) Confining pressure $=400 \mathrm{kPa}$

\section{Figure 3}

Deviatoric stress and axial strain curves of loess samples under different values of $\mathrm{pH}(\mathrm{CD})$. 


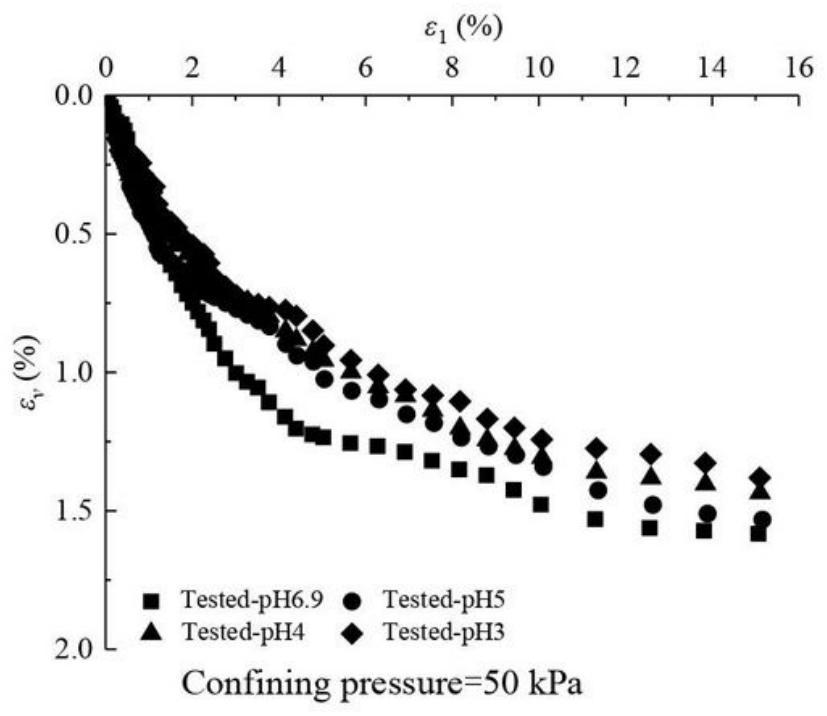

(a) Confining pressure $=50 \mathrm{kPa}$

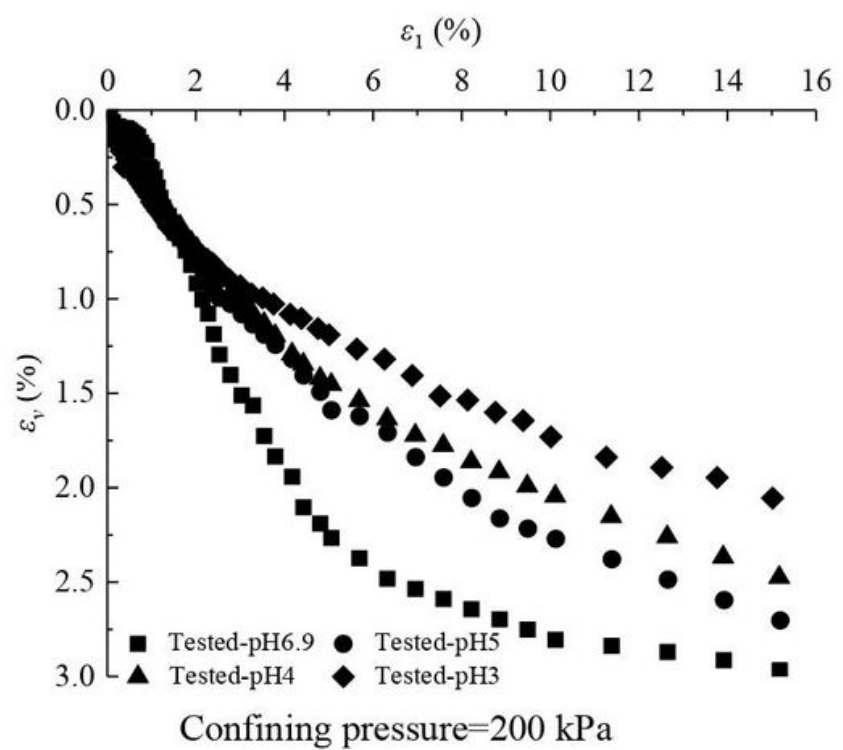

(c) Confining pressure $=200 \mathrm{kPa}$

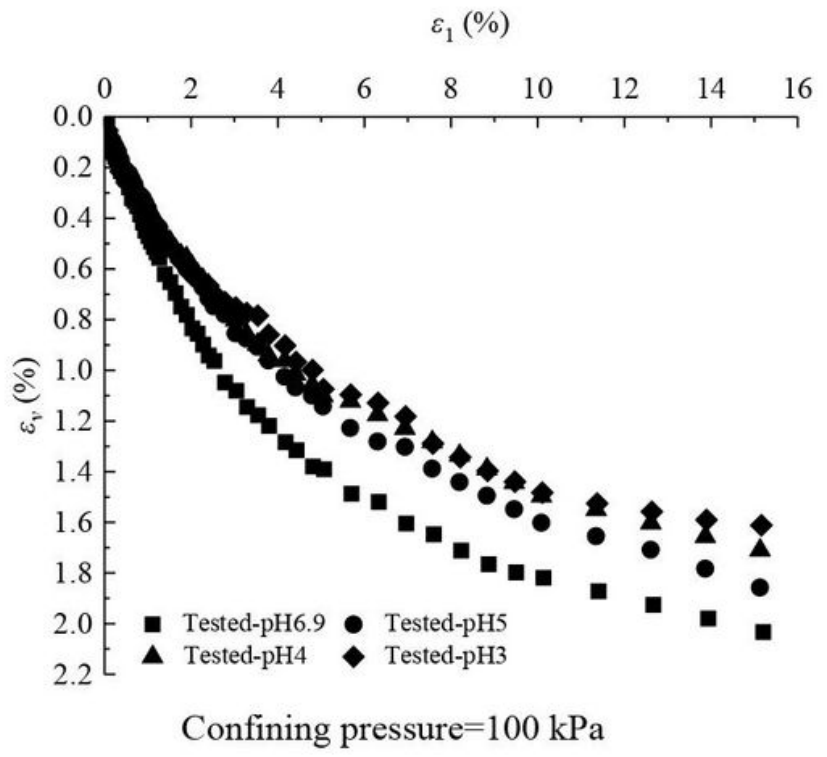

(b) Confining pressure $=100 \mathrm{kPa}$

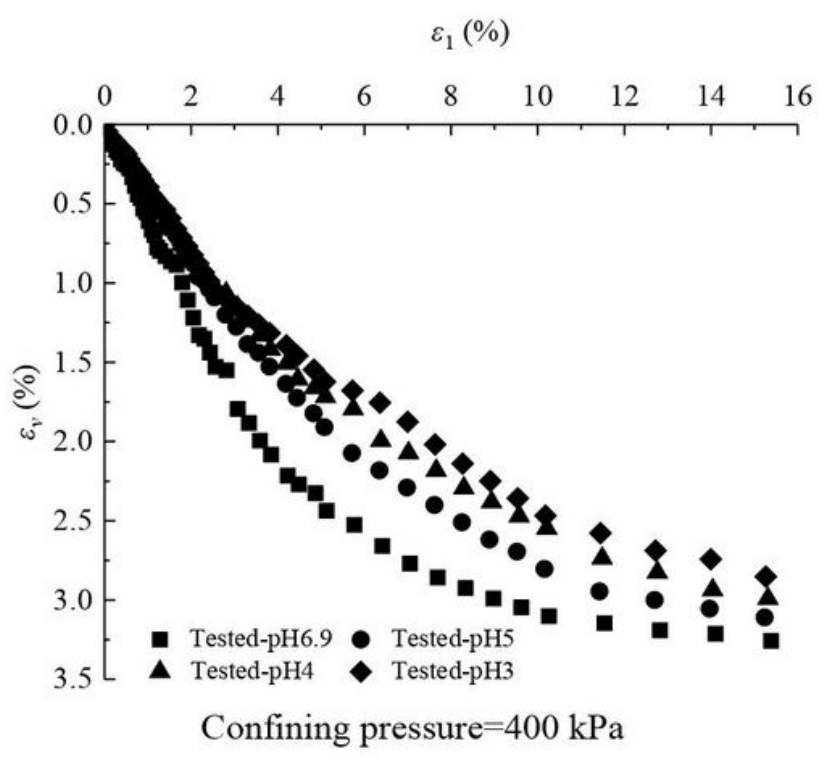

(d) Confining pressure $=400 \mathrm{kPa}$

\section{Figure 4}

Volumetric strain and axial strain curves of loess under different $\mathrm{pH}(\mathrm{CD})$. 


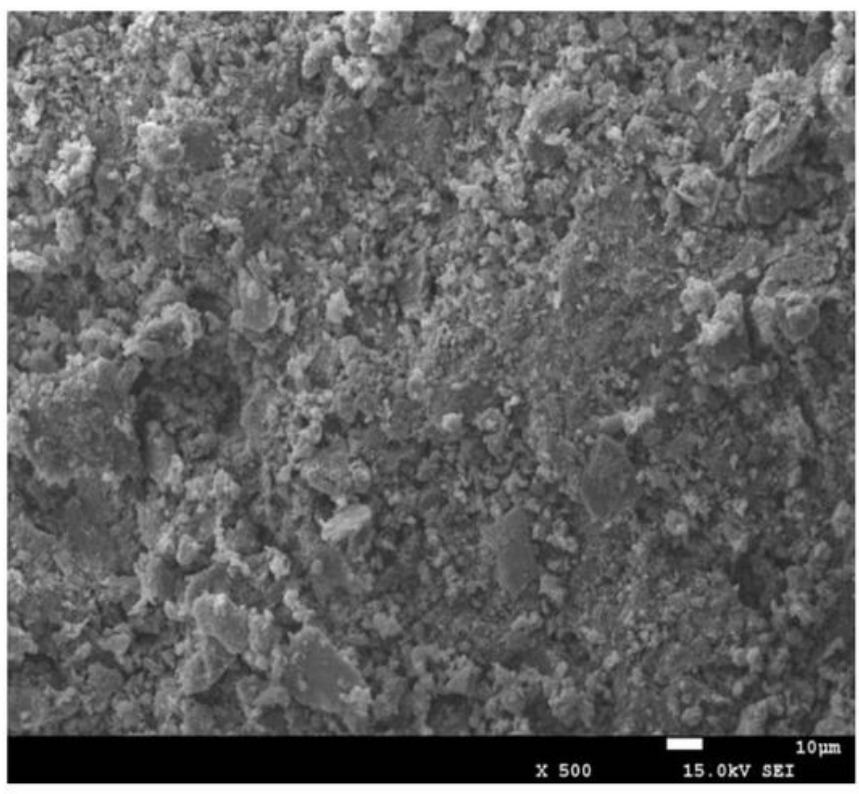

(a) $\mathrm{pH} 6.9$

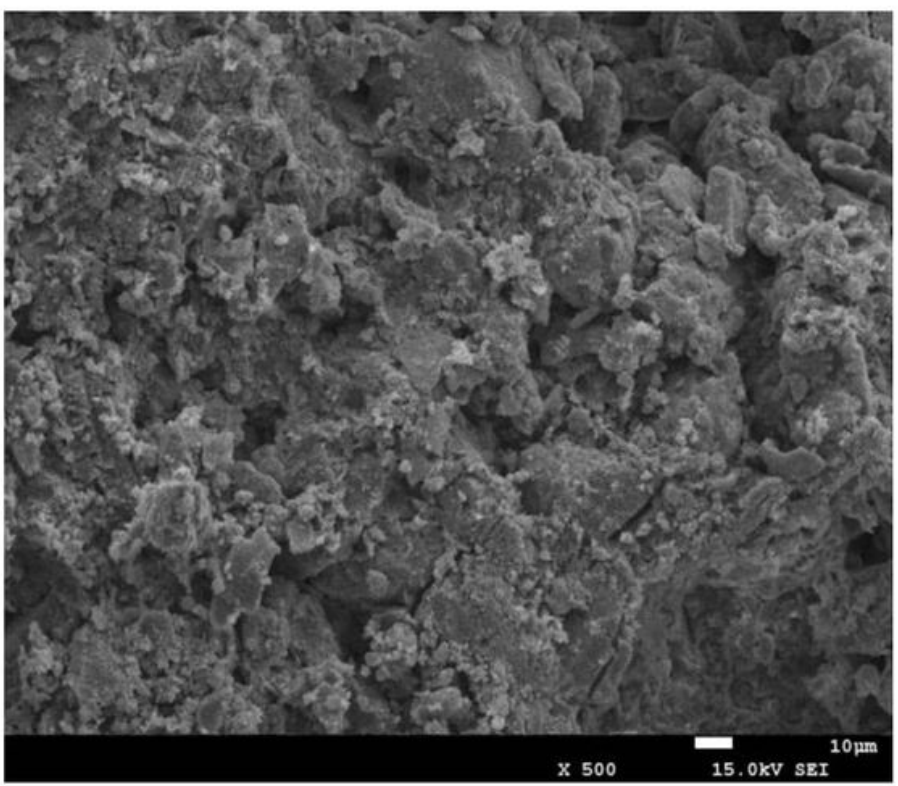

(c) $\mathrm{pH} 4$

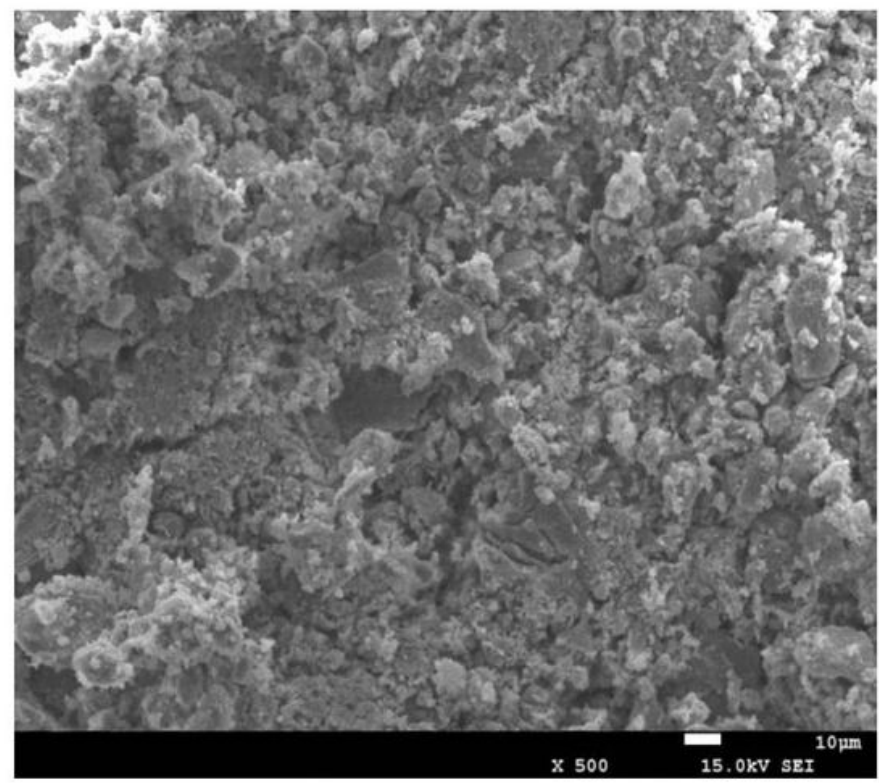

(b) $\mathrm{pH} 5$

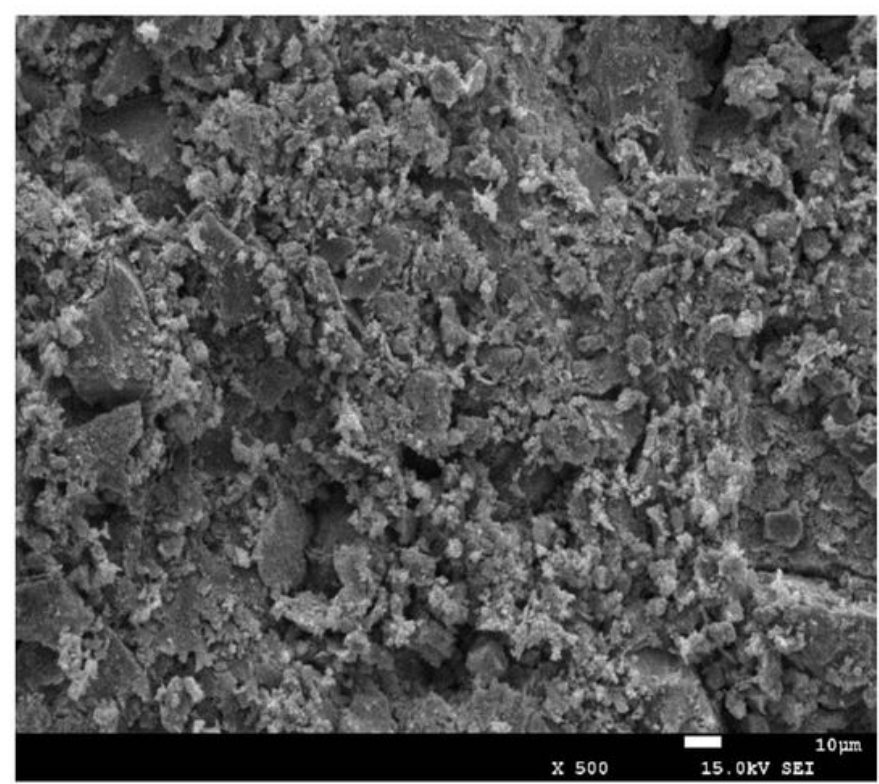

(d) $\mathrm{pH} 3$

\section{Figure 5}

SEM micrographs of loess samples under acid rain conditions. 
pH 6.9

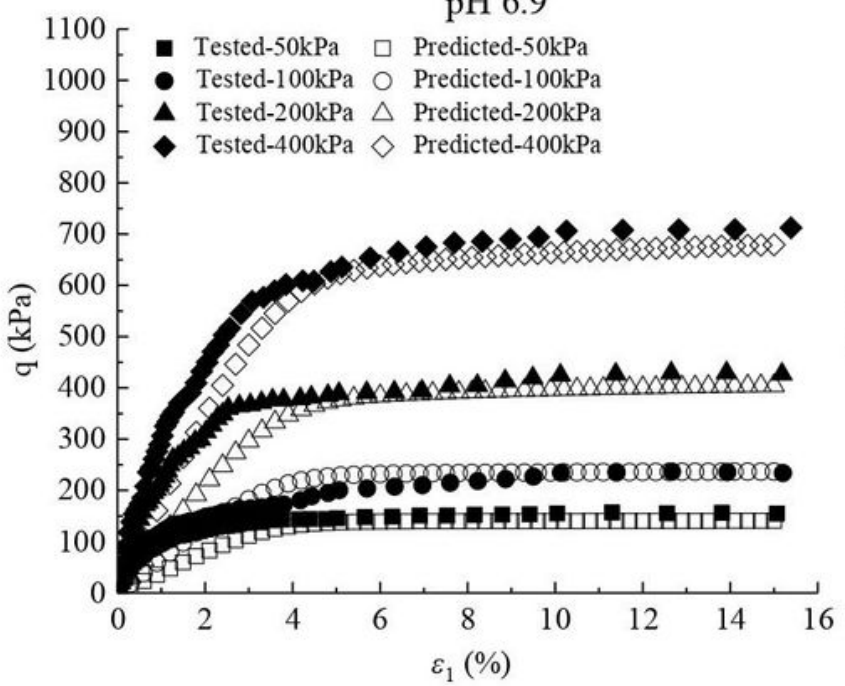

(a) $\mathrm{pH} 6.9$

$\mathrm{pH} 4$

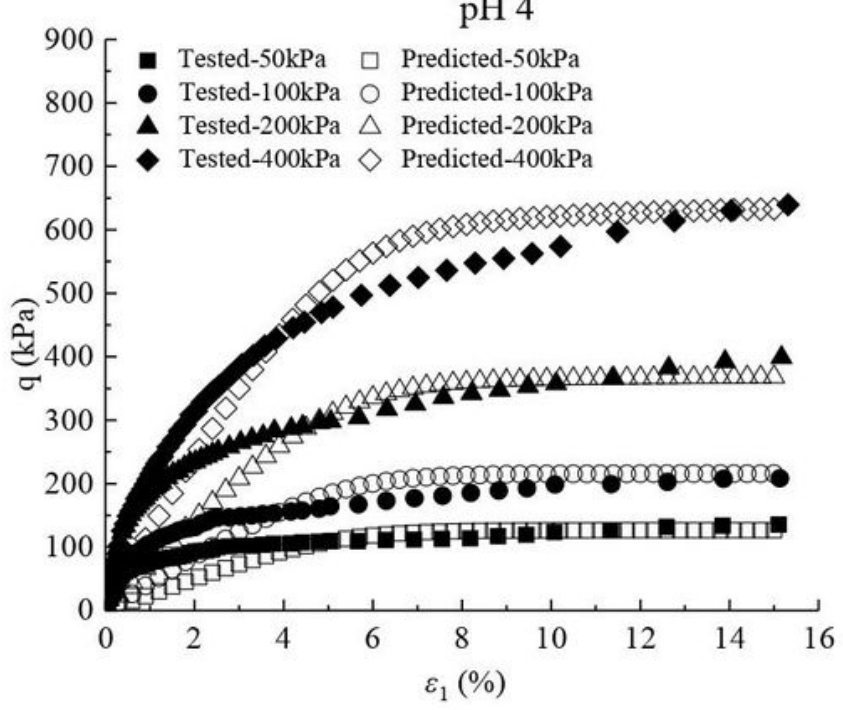

(c) $\mathrm{pH} 4$

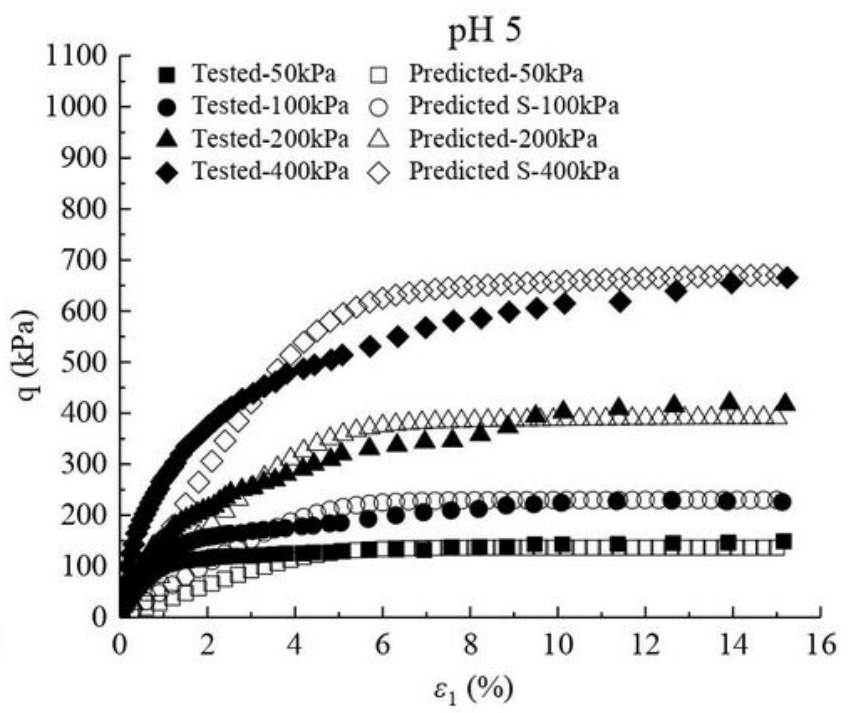

(b) $\mathrm{pH} 5$

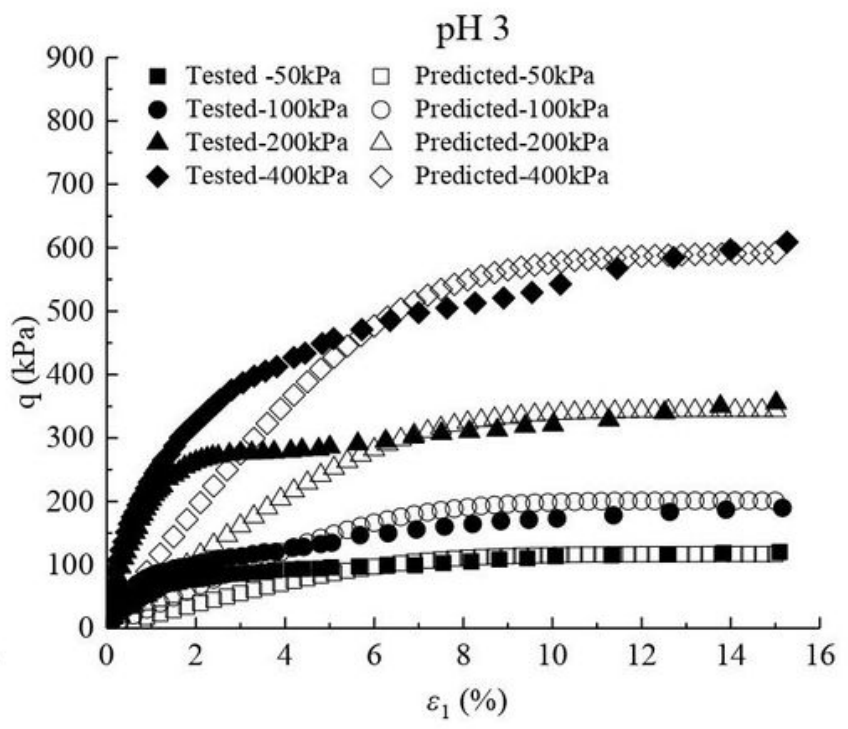

Figure 6

Deviatoric stress and axial strain for tests and simulations (CD). 


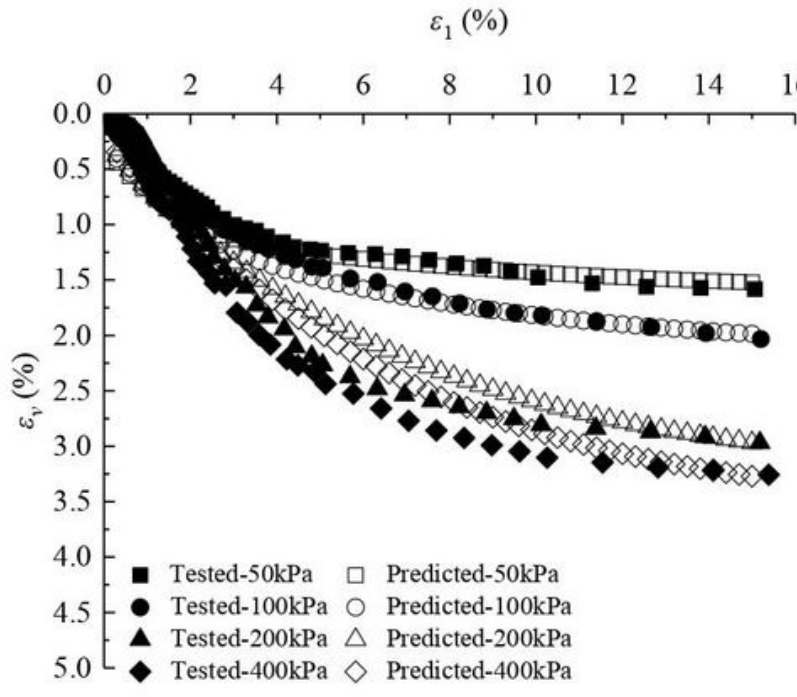

pH 6.9

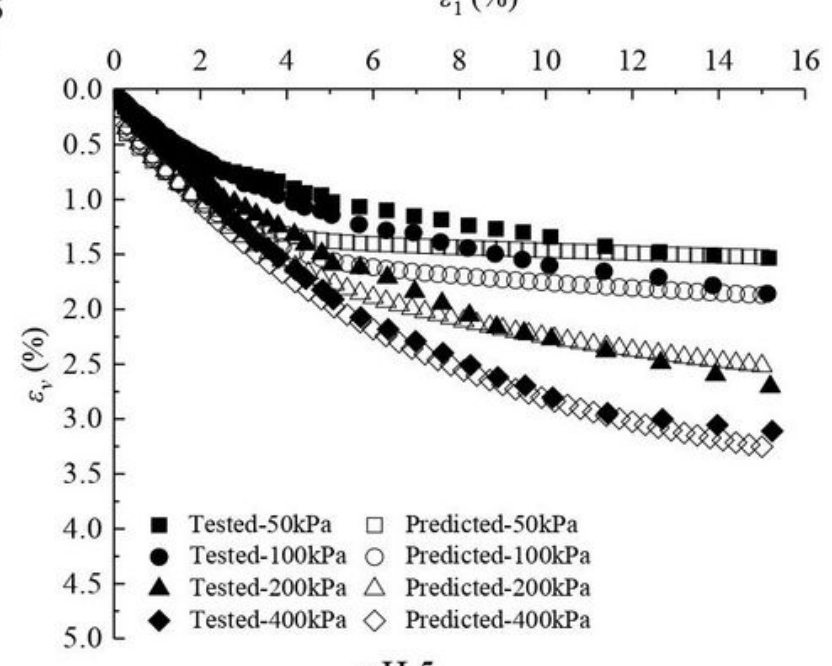

pH 5 (a) $\mathrm{pH} 6.9$

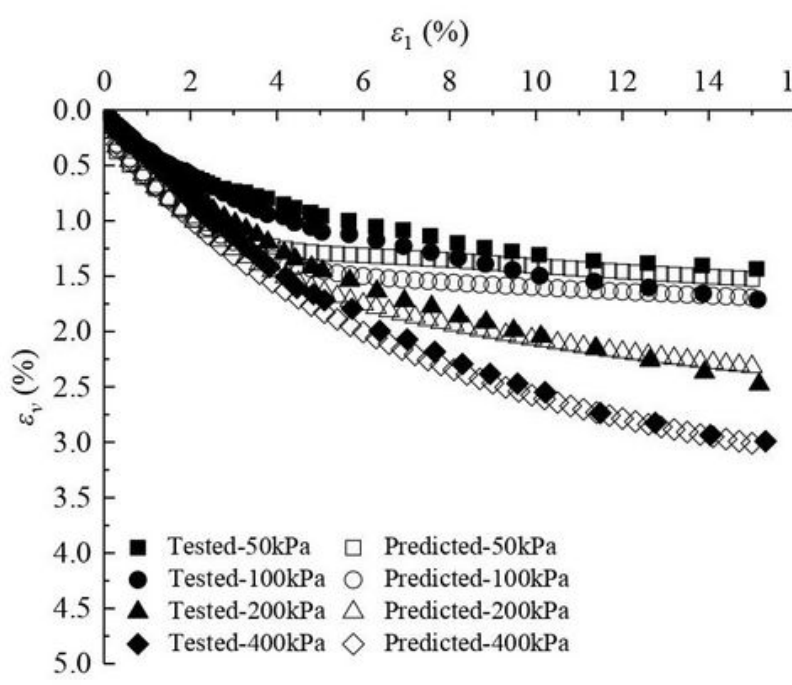

$\mathrm{pH} 4$ (b) $\mathrm{pH} 5$

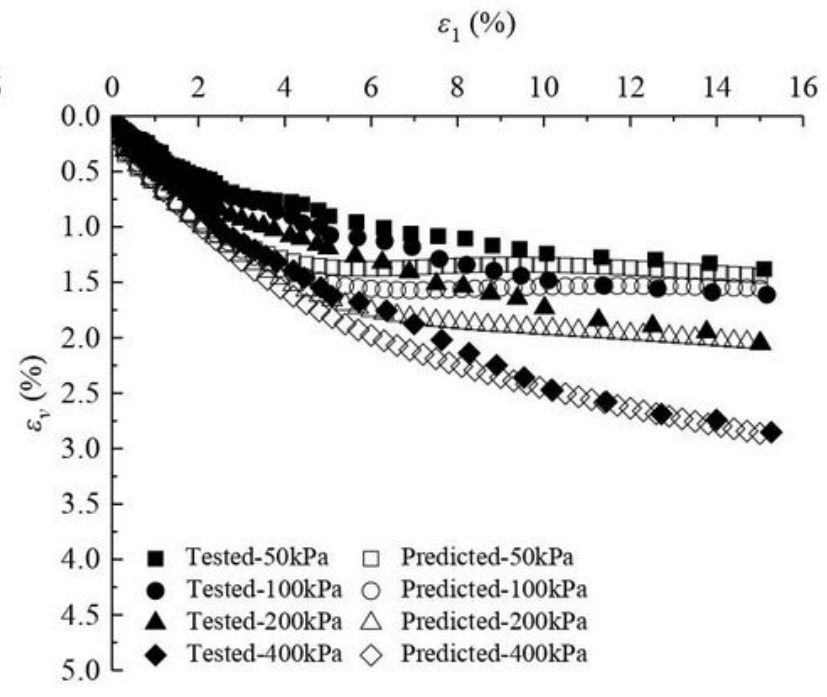

pH 3

(c) $\mathrm{pH} 4$

(d) $\mathrm{pH} 3$

\section{Figure 7}

Volumetric strain and axial strain for tests and simulations (CD). 


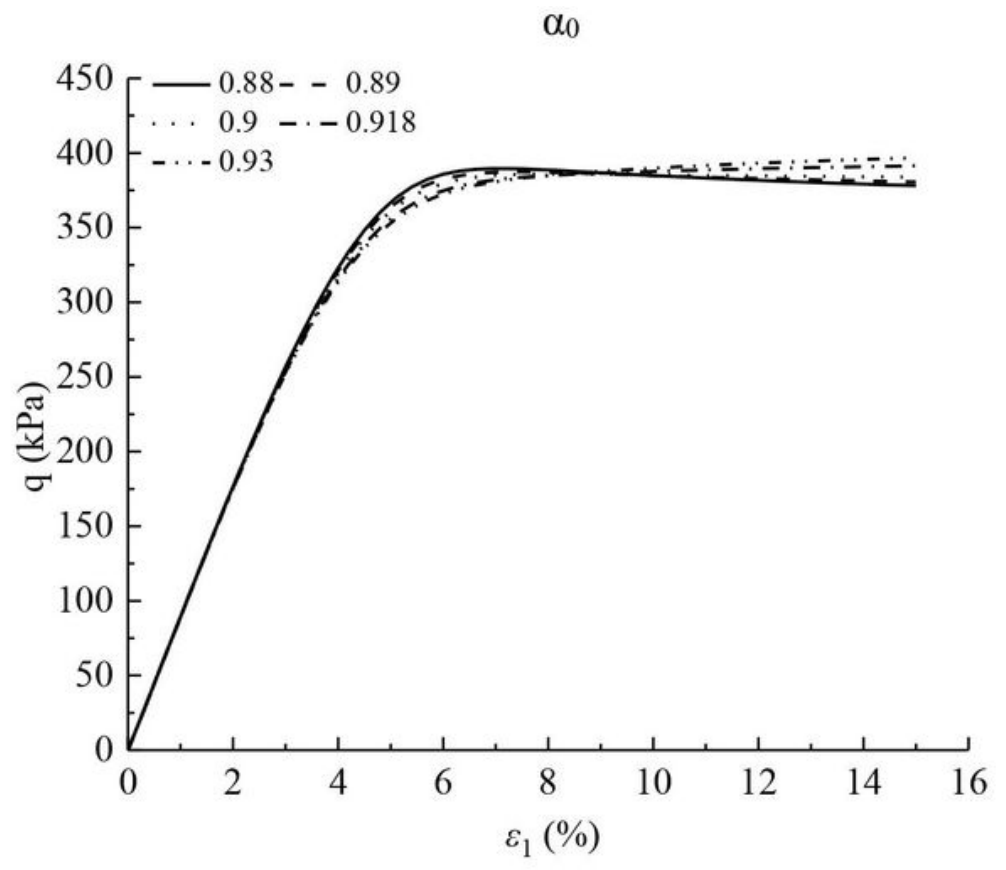

(a) Deviatoric stress and axial strain

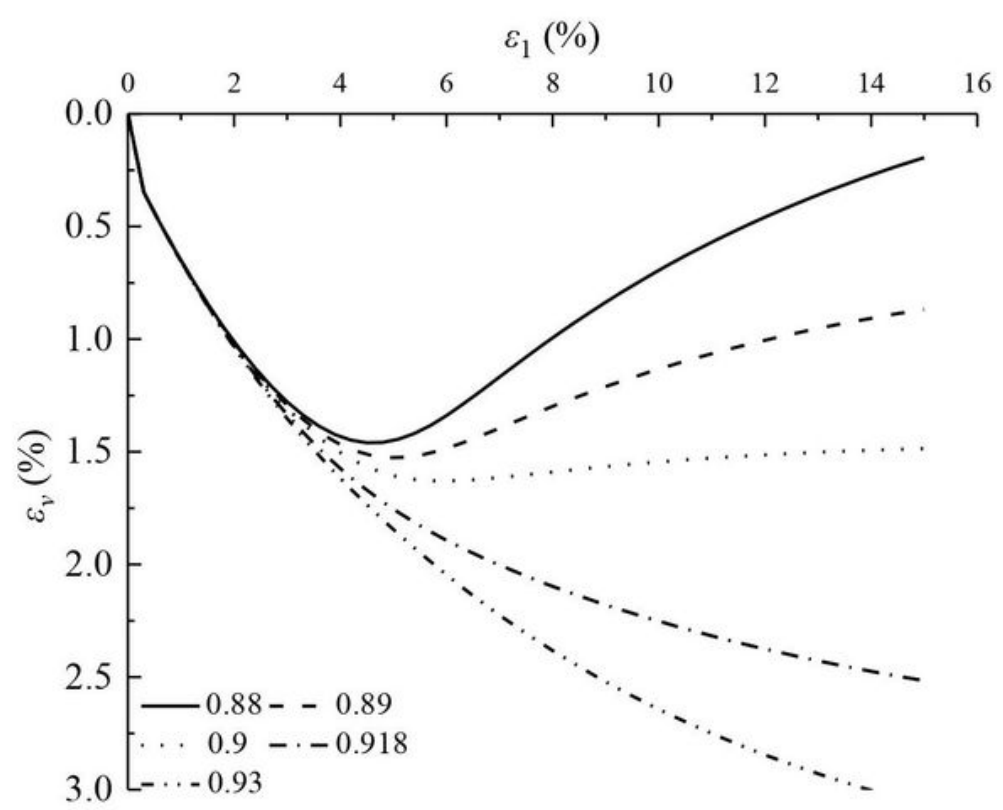

$\alpha_{0}$

(b) Volumetric strain and axial strain

Figure 8

Simulated results with varying a_0 


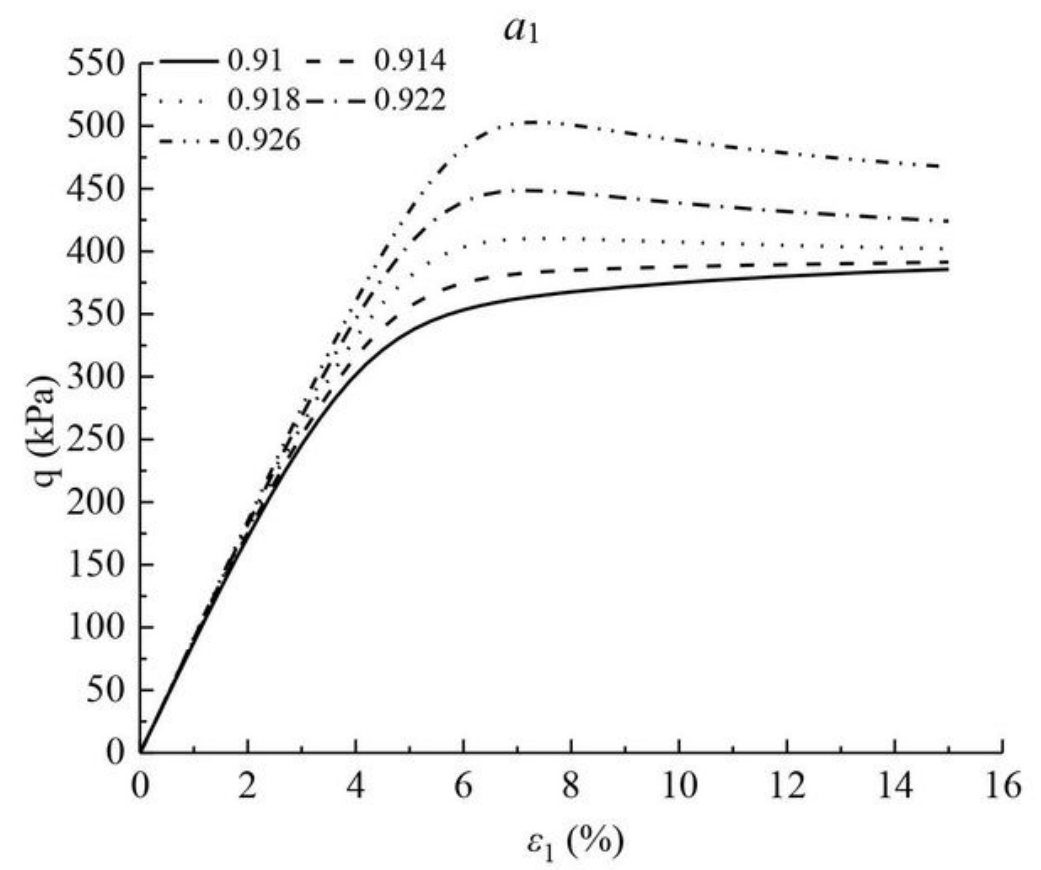

(a) Deviatoric stress and axial strain

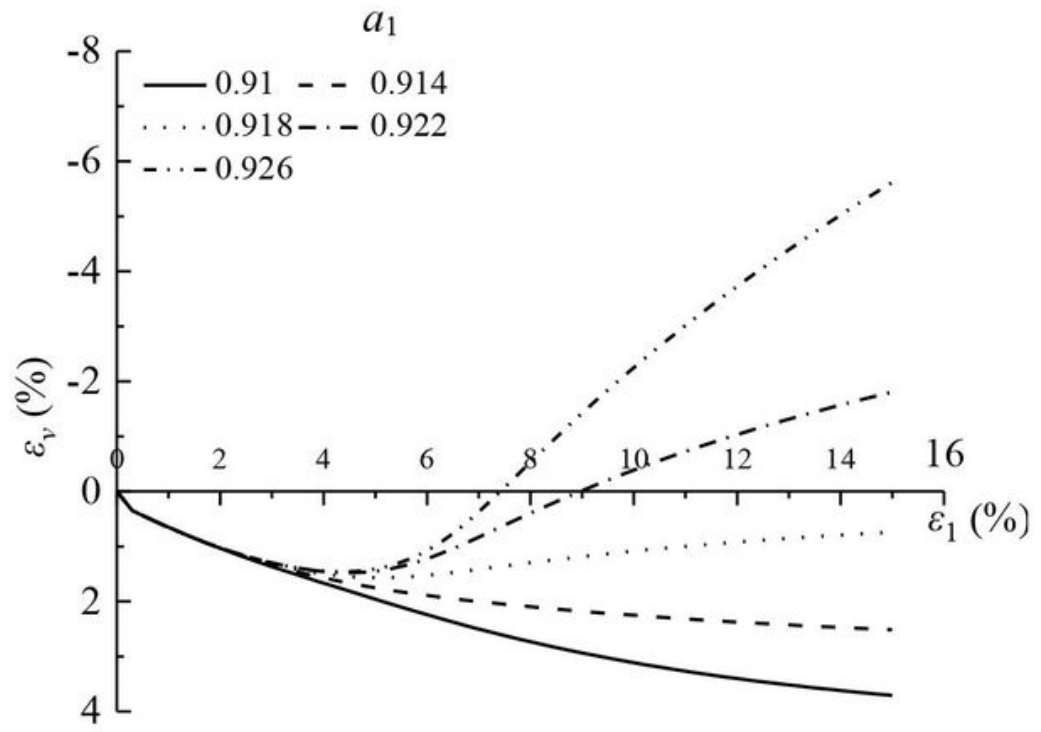

(b) Volumetric strain and axial strain

\section{Figure 9}

Simulated results with varying a_1 


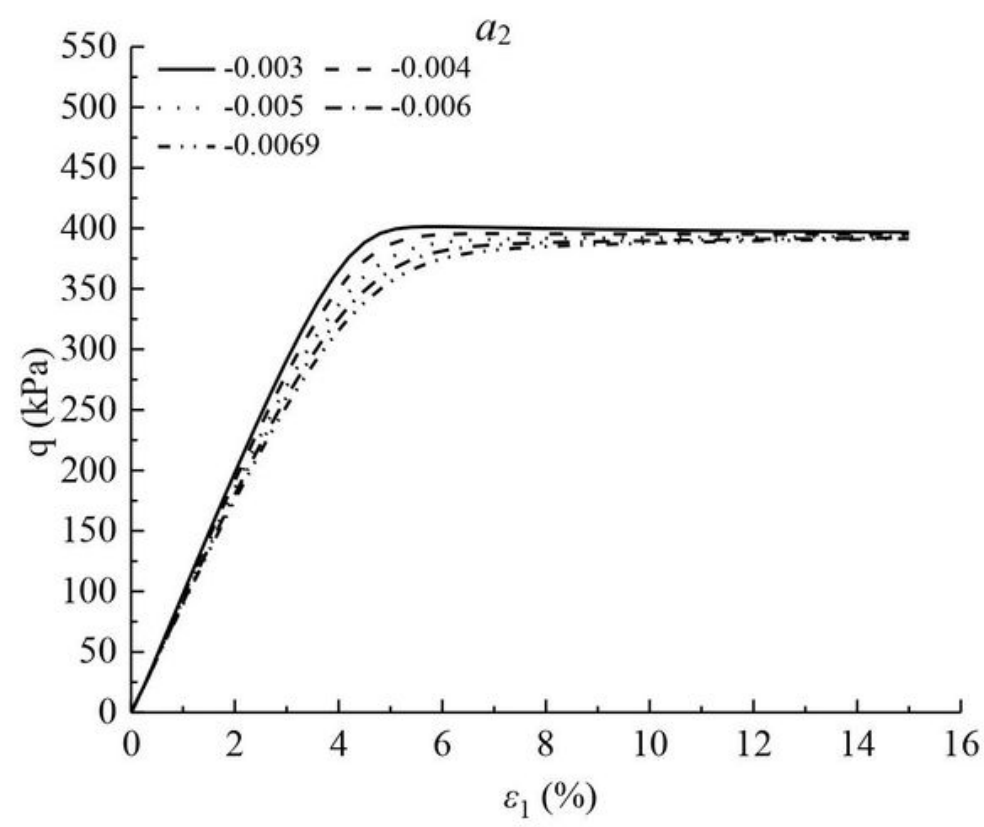

(a) Deviatoric stress and axial strain

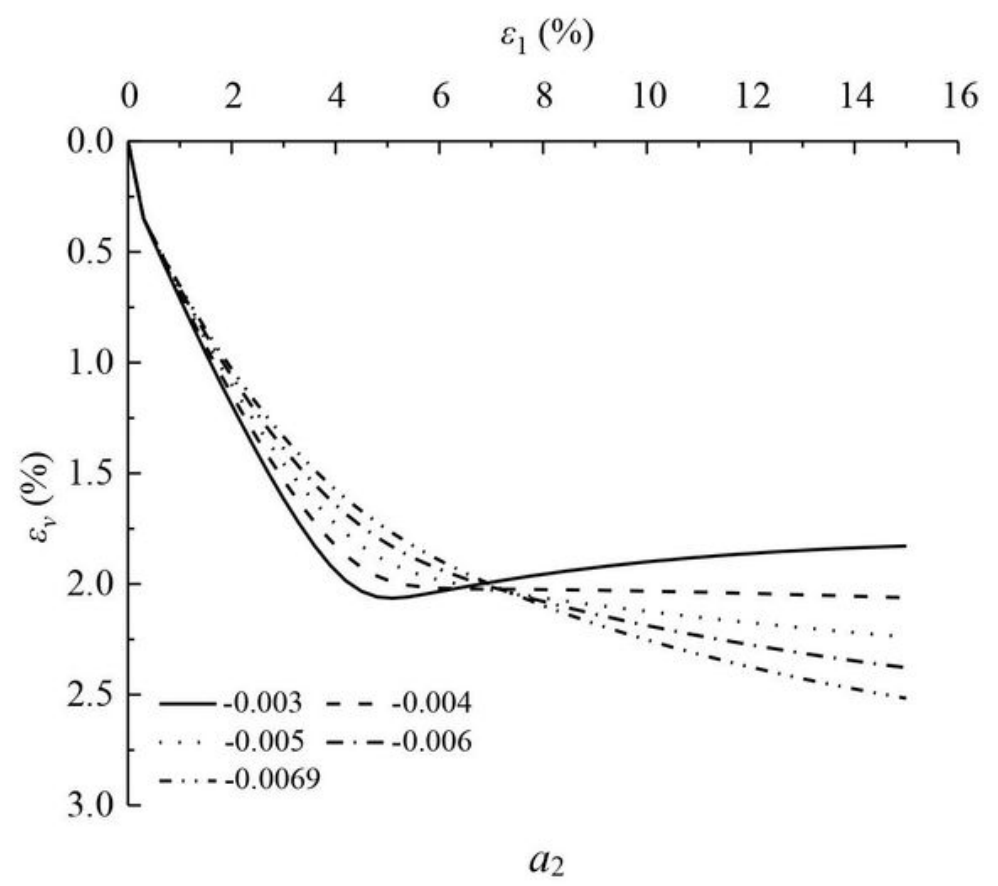

(b) Volumetric strain and axial strain

Figure 10

Simulated results with varying a_2 


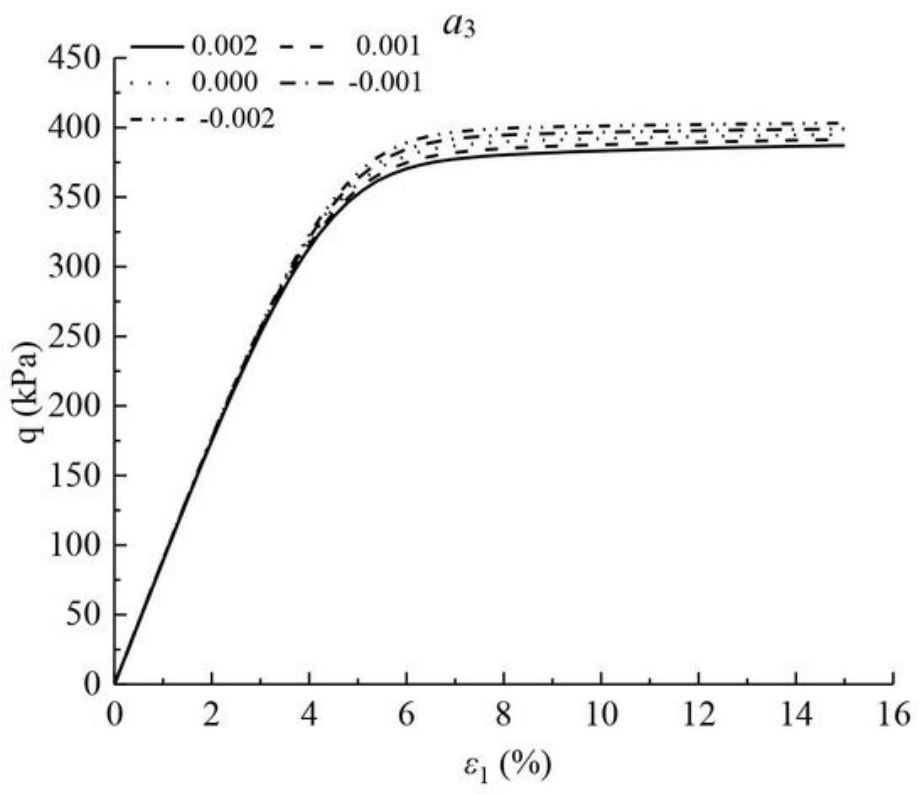

(a) Deviatoric stress and axial strain

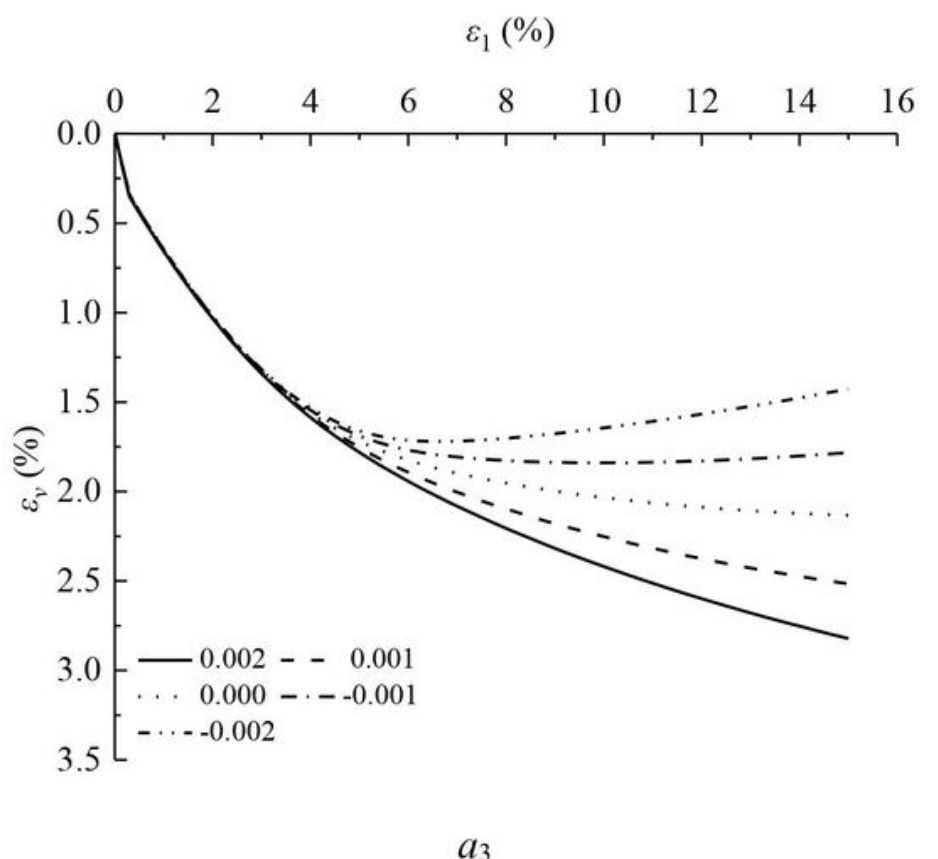

(b) Volumetric strain and axial strain

\section{Figure 11}

Simulated results with varying a_3 


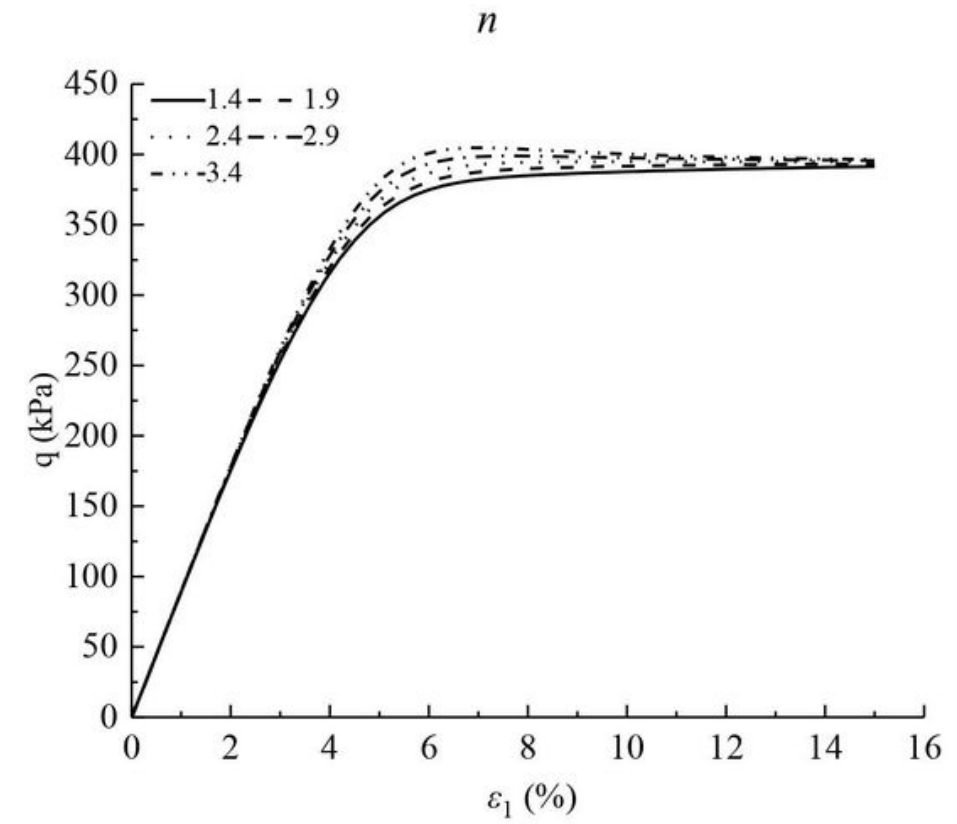

(a) Deviatoric stress and axial strain

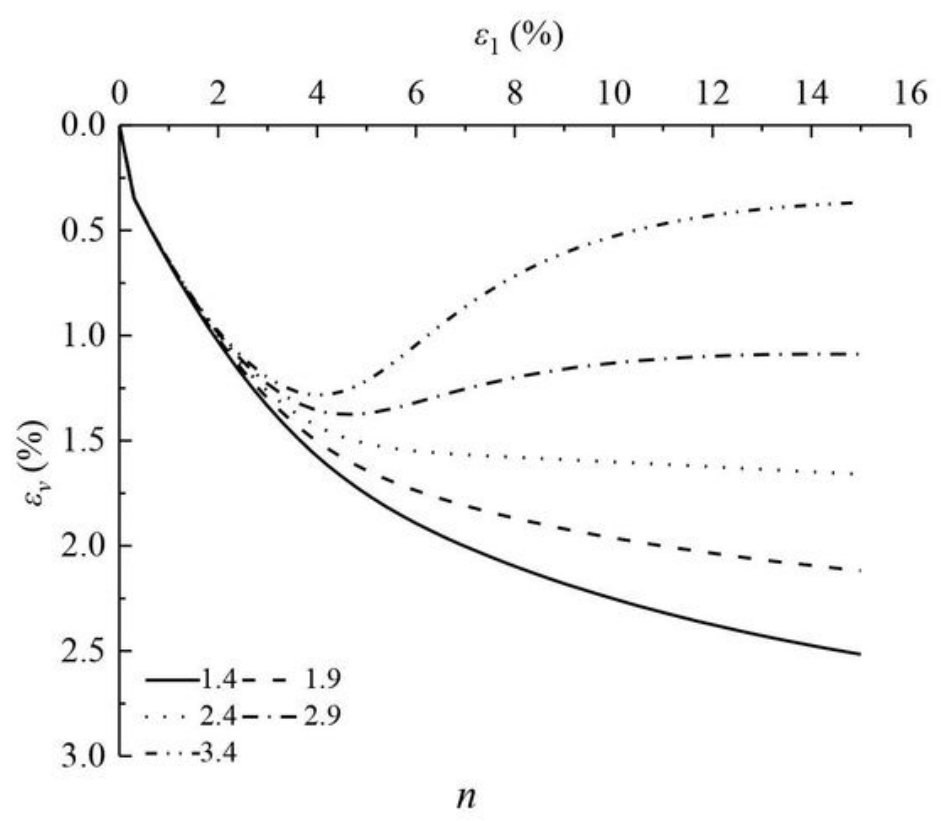

(b) Volumetric strain and axial strain

\section{Figure 12}

Simulated results with varying $n$ 


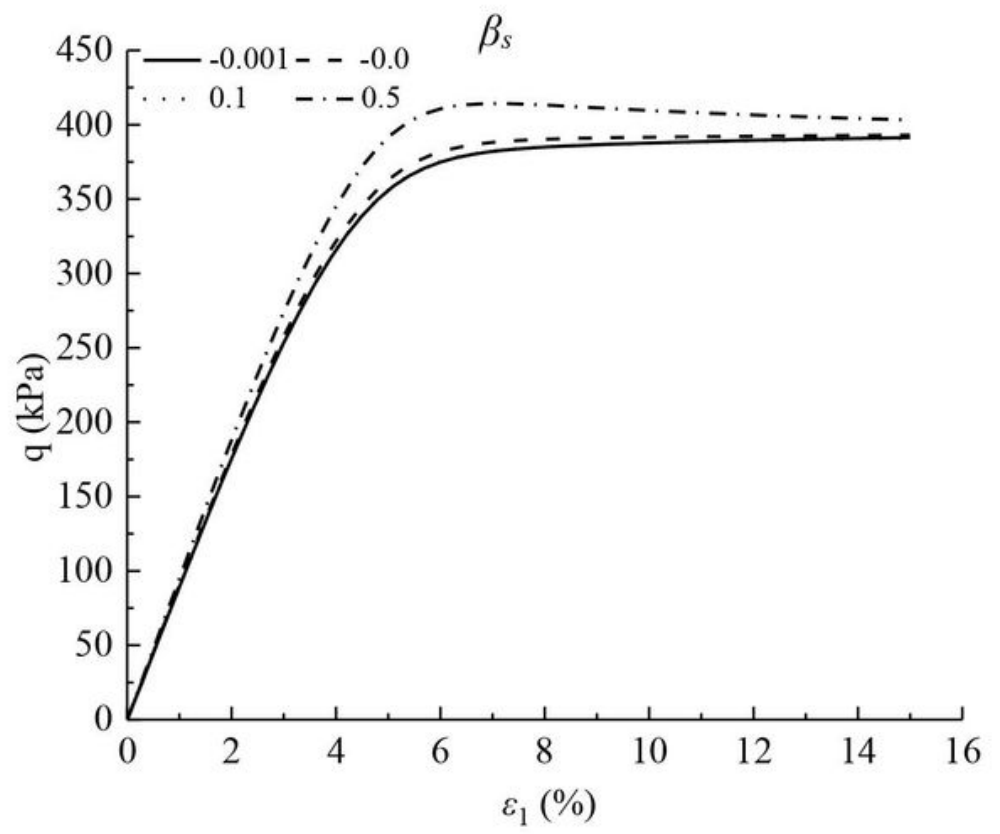

(a) Deviatoric stress and axial strain

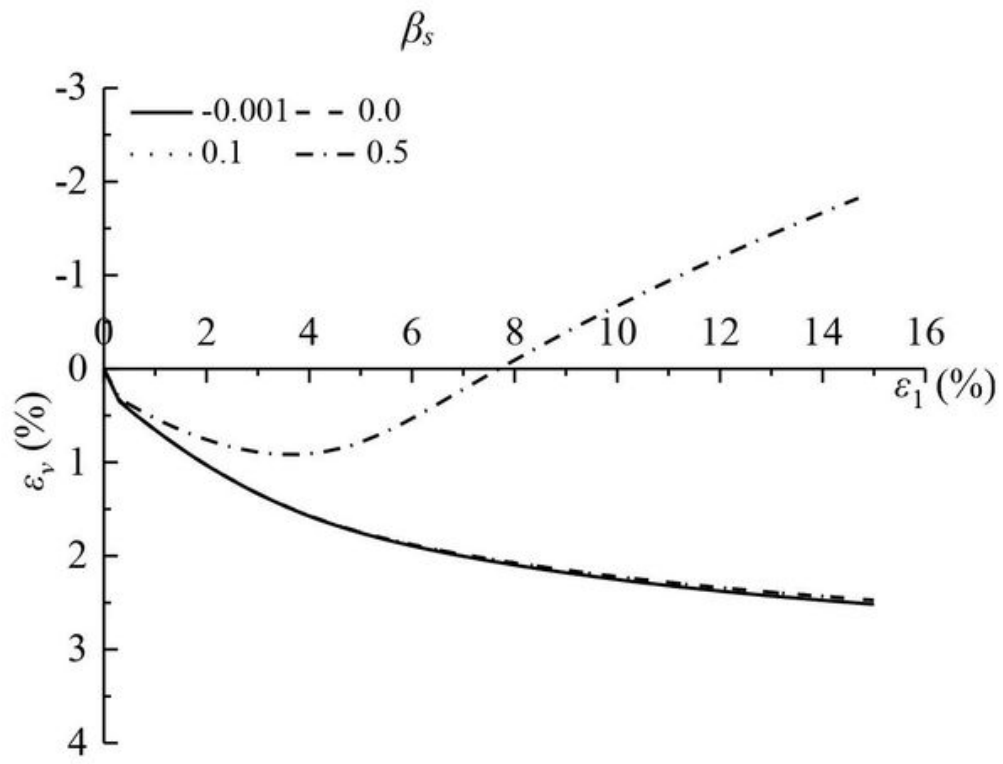

(b) Volumetric strain and axial strain

Figure 13

Simulated results with varying $\beta \_s$ 


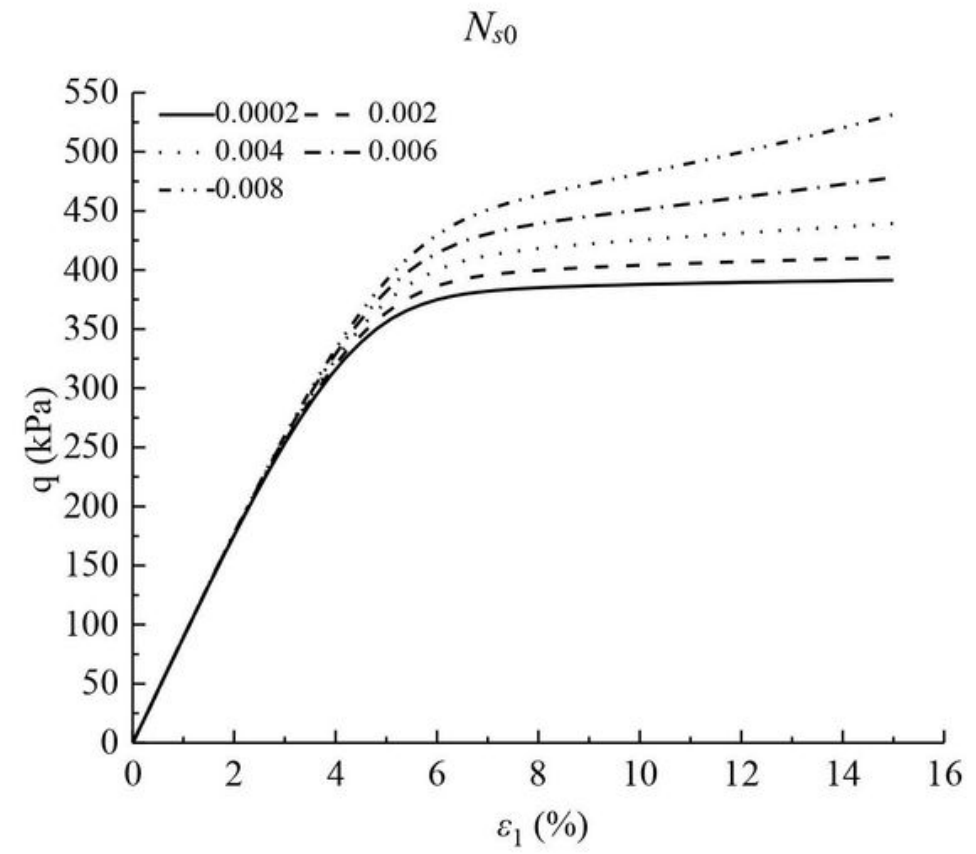

(a) Deviatoric stress and axial strain

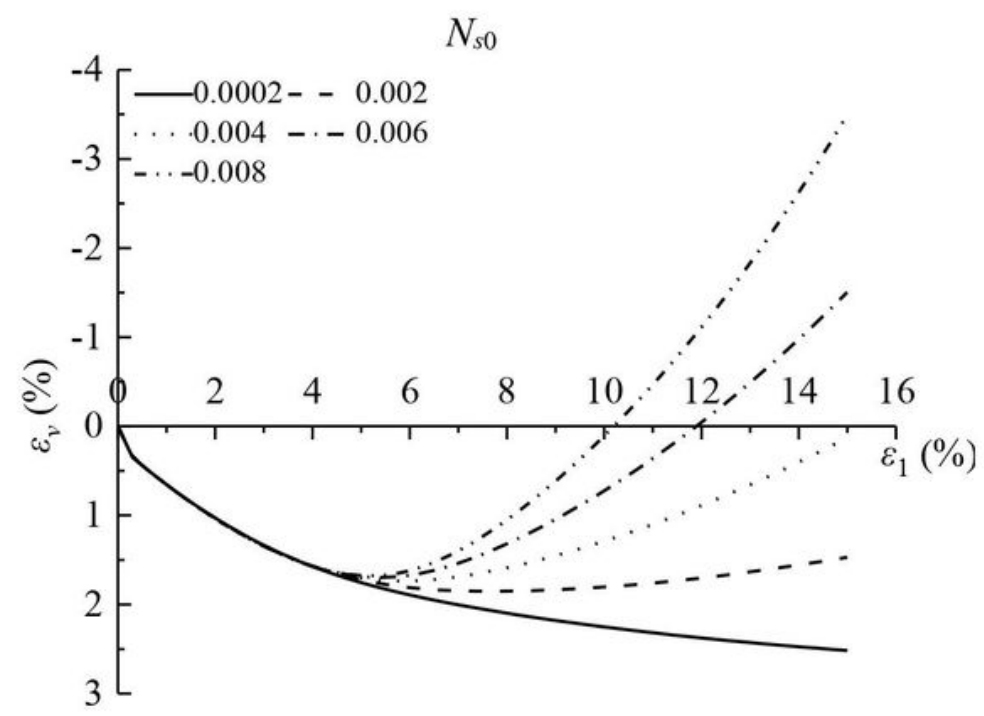

(b) Volumetric strain and axial strain

\section{Figure 14}

Simulated results with varying N_s0 